\title{
Margin Trading: Hedonic Returns and Real Losses
}

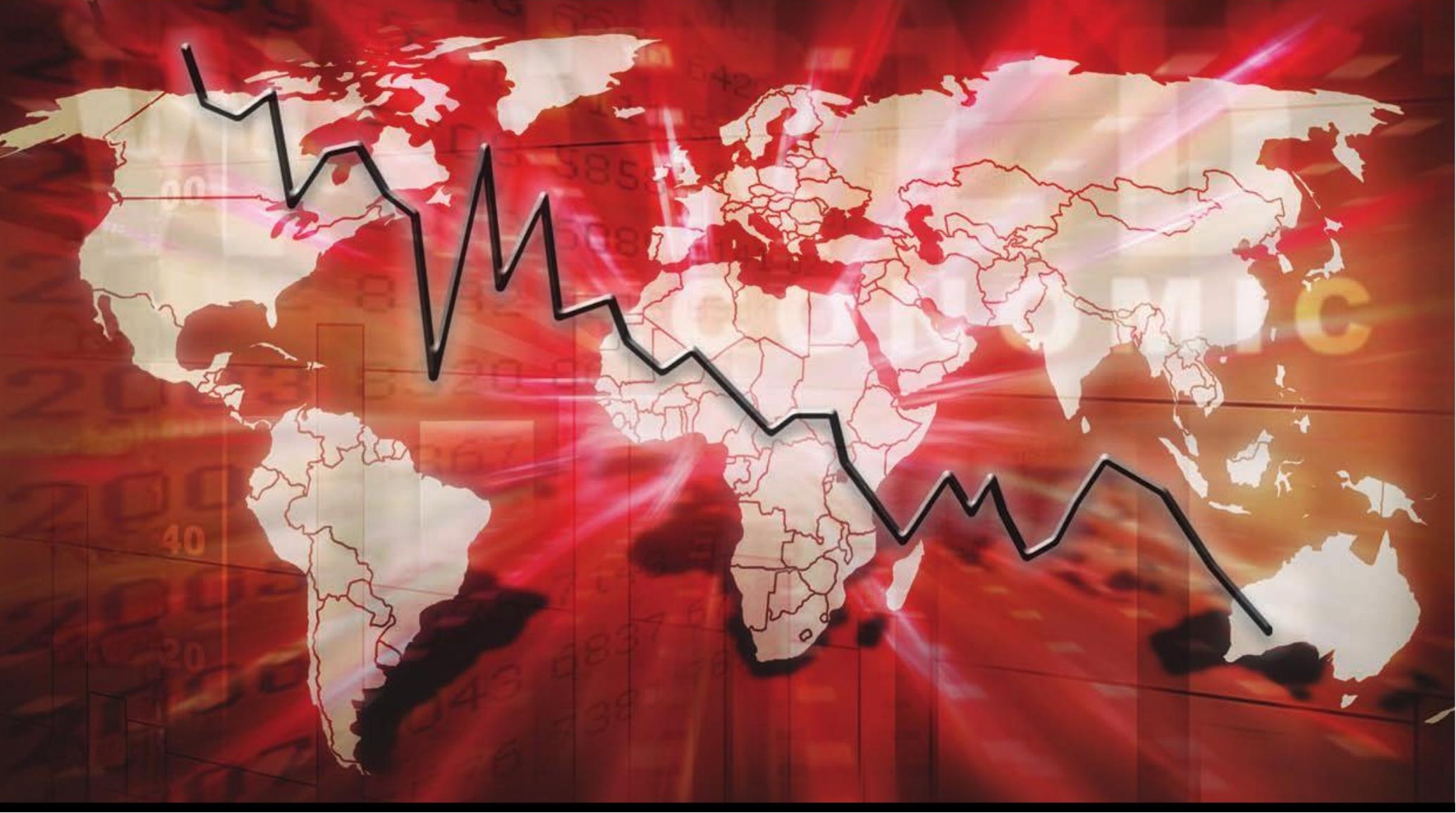

Daniel Ladley, University of Leicester Guanqing Liu, University of Leicester James Rockey, University of Leicester

Working Paper No. 16/06 


\title{
Margin Trading: Hedonic Returns and Real Losses
}

\author{
Daniel Ladley* \\ University of Leicester
}

\author{
Guanqing Liu ${ }^{\dagger}$ \\ University of Leicester
}

10th April 2016

\author{
James Rockey ${ }^{\ddagger}$ \\ University of Leicester
}

\begin{abstract}
Margin trading is popular with retail investors around the world. This is a puzzle, since, as we show, it has a negative expected return. Our explanation is that whilst lowering mean returns, the collateral requirement imposed by margin calls induces positive skew in the distribution of returns. Investments in assets with symmetric returns now offer limited losses and a small chance of a large gain, like lottery tickets and other gambles. Results from a unique dataset of retail futures traders show that actual losses are substantial. Traders' behaviour is demonstrated to be best understood as motivated by hedonic returns.
\end{abstract}

Keywords: Margin Trading, Hedonic Trading, Gambling, Recreational Investors

JEL-Codes: G02, G11, G13

*d.ladley@le.ac.uk

†g180@le.ac.uk

¥james.rockey@le.ac.uk. We thank seminar participants at Leicester and the RES Sussex. The usual disclaimer applies. 


\section{Introduction}

The Little Crash in '62, as described in the classic account of Brooks (2014), was the result of limited liquidity and panic. In particular it was the result of the limited liquidity and panic of retail investors trading on the margin; that is, trading mostly with borrowed money secured with a small amount of collateral. Kindleberger (2000) identifies a similar role for margin traders and their brokers in the 1929 Crash. ${ }^{1}$ Brunnermeier and Pedersen (2009) discuss their role in more recent crises. Margin trading, however, remains a common but relatively understudied feature of financial markets. This is perhaps surprising because, as this paper shows, margin trading, by retail investors, leads to significantly lower but skewed returns.

Regardless of whether a crash is transitory like in '62, or not as in '29, liquidity spirals as described anecdotally by Brooks (2014) and formally by Brunnermeier and Pedersen (2009), leading to the ruin of many margin investors. Of course, in such large crises, many investors suffer (and many profit); but as we will study formally, margin traders risk the loss of their entire investment even in markets with low volatility. Given then, the obvious hazards of trading on the margin, the natural question is, why is margin trading ubiquitous? Our explanation is that the collateral requirement imposed by margin calls induces positive skewness in the distribution of these returns, making such investments more similar to a lottery. Investments in otherwise low risk assets will now offer lower average returns but with limited losses and a small but positive chance of a large gain. Thus, the continuing appeal of margin trading is that reduced financial gains are compensated by the hedonic returns accruing from the positive skew in the distribution of returns that margin trading induces. We test this hypothesis using a unique dataset on the full trading histories of traders on the Shanghai Futures Exchange (SHFE). We show that traders incur large losses (average returns are -27\%) and their trading behaviour and choices would be extremely hard to rationalise without a hedonic motive.

This explanation builds on the findings of a prominent recent literature which studies the motivations and behaviour of retail traders. ${ }^{2}$ Since such routine trading is known to be 'Hazardous to Your Wealth' (see the seminal papers of Barber and Odean (2000), and Barber et al. (2009))

\footnotetext{
${ }^{1}$ Brooks (2014) describes how the Dow Jones incurred its second largest ever loss on the Monday and fell further on Tuesday morning. That afternoon, however, the market started to recover, and its losses had been eliminated completely one trading day later by the end of Thursday. Brooks, citing the NYSE official reports, emphasises the role of private individuals' behaviour in precipitating the crash and the majority of private investors traded on the margin. As the market fell, reducing the value of their portfolios and thus eliminating their collateral, these investors - presumably unable or unwilling to provide additional collateral - were issued margin calls and forced by their brokers to liquidate their positions to eliminate their debts. Many had already faced such calls over the prior weekend, providing the initial downwards acceleration. The large volume of selling induced by this led to further price falls, further margin calls, and a downwards spiral. In Brooks's account, the precipitous fall in the market - so rapid the Dow Jones ticker tape was unable to keep up - was arrested only by the entry of institutional investors who perceived value in the market, and who crucially, had ample liquidity.

${ }^{2}$ Non-professional individuals who trade or invest small amounts of their own money through brokerages.
} 
the available explanations are that these investors are either irrational - say because they weight probabilities inaccurately (see, Barberis, 2012) - or are deriving some other, non-pecuniary, benefit from their trading. In other words, they enjoy the experience (see, Barberis and Xiong, 2012, Ingersoll and Jin, 2012, Dorn and Sengmueller, 2009, Dorn et al., 2015). ${ }^{3}$ Altering the distribution of returns, trading on the margin makes investment more entertaining.

This explanation is consistent with a small but prominent literature that studies trading as gambling. An important early contribution was that of Golec and Tamarkin (1998) who showed that investors prefer so called lottery stocks (again, those with high skewness in the returns). Subsequent work has shown that lottery-ticket purchasers tend to buy lottery-type stocks, (see, Kumar, 2009) and investors in regions with a greater proportion of Catholics compared to Protestants and thus fewer religious presumptions against gambling trade more lottery type stocks, (see, Kumar et al., 2011). Similarly, investors who say they enjoy investing are found to trade more (Dorn and Sengmueller, 2009); option prices reflect retail investors compensating intermediaries for additional risk for lottery type payoffs (Boyer and Vorkink, 2014); and investors trade less, especially in lottery stocks when lottery prizes are large (see, Gao and Lin, 2015, Dorn et al., 2015). ${ }^{4}$ That traders' losses are so large is also consistent with the idea that individuals will exhibit non-standard preferences only temporarily or else they will incur increasing losses (see, Azevedo and Gottlieb, 2012, Jayaraman et al., 2016).

Read together, this literature constitutes a body of evidence that an important motivation for individual traders is hedonistic - it provides a similar type of entertainment as lottery tickets, or other gambles. This evidence is, whilst convincing, in an important sense indirect. That is, the hedonistic nature of the trading behaviour is inferred from its correlates e.g. when lotteries are more available, or of larger value, we observe less trading. Moreover, in places where we expect fewer gamblers we observe fewer gambling traders, and indeed traders who say they enjoy gambling/trading are seen to do it more.

This paper provides the first direct evidence of participation in financial markets as a source of entertainment. In particular we will focus on the trading of Rebar futures on the Shanghai Futures Exchange (SHFE). ${ }^{5}$ We use a unique database of the full portfolio histories of individual clients of a leading Chinese retail brokerage. We show that the returns obtained from margin trading of

\footnotetext{
${ }^{3}$ Investors' utility functions were originally analysed in the classic papers of Friedman and Savage (1948) and Markowitz (1952), since the seminal work of Shiller and others (see, Shiller (2000) for a survey), these have been generalised to incorporate insights from Behavioural Economics and elsewhere - such as prospect theory Barberis and Huang (2008) for an excellent example. Other forms of motivation, such as the competitiveness preferences proposed by Parco et al. (2005) and Sheremeta (2010) may also play a role but there is no evidence for such behaviour in a large and anonymous context such as we study.

${ }^{4}$ Bhattacharya and Garrett (2008) provide evidence that lotteries that offer more skewness offer lower returns, suggesting a similar trade-off.

${ }^{5}$ Rebar are reinforcing steel bars, widely used with concrete in the construction of buildings.
} 
Rebar futures are consistent only with a substantial hedonic motive and are not rationalisable as an investment. We will see that margin-trading means that the returns to any underlying asset are transformed to have a lottery-type distribution. This is because, the rules of the SHFE and other exchanges, operate a system of margin-calls by which the maximum debt of the trader is limited. If a trader fails to produce additional capital given a fall in the value of their portfolio then this portfolio is closed. This means that the distribution of returns is truncated on the lefthand-side leading to skewed lottery type returns. One implication of this is that different margin requirements alter the lottery-ness of the activity. We will show that the expected return of investing on the margin is negative, and that there no optimal portfolio of which margin traded Rebar futures are a part exists, ruling out more sophisticated portfolio diversification strategies. Having thus established that the investment properties of margin trading are similar to those of gambling - a highly skewed distribution of returns with a negative expectation, and with no use as part of a portfolio - we will then show that the nature of the trading behaviour is consistent with entertainment but not investment. Trades tend to be limited to a small period each day, with the average position held for around an hour and a half. Further, traders seem to gamble a fixed-pot, after which they leave the market for some time.

The literature on margin trading is relatively limited. Notably, Brunnermeier and Pedersen (2009) use a formal model to understand the effects of margin trading on markets. In their model, market liquidity interacts with the ability of investors to borrow to trade. They show how this interaction can destabilise markets, increase volatility and induce 'liquidity spirals' like those in '29, '62, as well as those from the early 1980's onwards that they describe in their study. Their paper thus provides an important contribution to understanding the aggregate effects of margin trading, which our paper seeks to complement by understanding the micro-foundations of the decision to trade on the margin. Recent empirical work has sought to shed further light on the relationship between margin trading and liquidity. Kahraman and Tookes (2013) uses the staged introduction of margin trading for different assets in India to provide evidence that margin trading leads to a substantial reduction in the spread. On the other hand, Wang (2014) using data for Chinese ETFs, shows that allowing margin trading and short-selling can reduce liquidity by discouraging trading by uninformed investors. Heimer (2015) studies the impact of leverage constraints by comparing leverage-limited US traders with their unconstrained EU counterparts. By studying contemporaneously traded FX markets he shows that leverage constraints limit losses. In his view, leverage constraints serve to limit poor-decisions by over-confident traders. Our, not-contradictory, explanation is that lower leverage constraints mean expected returns are higher due to fewer margin 
calls. Heimer worries about over confidence; but, we are more sanguine and argue that the losses traders incur in the context we study may be understood as simply the price of the hedonic returns they enjoy. To support this view, we show that although traders' financial losses are substantial, that their behaviour is consistent with deriving considerable hedonic returns.

This paper is organised as follows. Section 2 demonstrates why margin trading should be associated with lower returns and more skewness, it also introduces our data. Section 3 shows that Rebar traded on the margin are never an optimal investment as part of a portfolio. Section 4 discusses key features of traders' behaviour to further advance the argument that they are largely motivated by hedonic returns. Section 5 concludes the paper.

\section{Margin Trading and Lotteries}

Traders, whether private individuals or institutions, can often use the assets they trade as collateral to finance other trades. Given that such assets are risky, they are unable to borrow the full value of these assets and must provide some additional collateral. For individual investors, this process often takes the form of a margin account in which investors are able to purchase assets up to the value of some multiple of the collateral they have provided. This limit is known as the margin requirement. For example a trader who posts $\$ 1,000$ of collateral with a margin requirement of $10 \%$ may purchase assets up to the value of $\$ 10,000$. This leverage will increase the variance of the returns, a $10 \%$ appreciation in the value of the assets now doubles the investor's initial collateral whilst a similar depreciation reduces it to zero. Losses, such as those in the second case, will increase the trader's leverage and so violate the margin requirement. As a result in the event of losses the trader is required to provide additional funds or their positions are closed to maintain the margin ratio. ${ }^{6}$ This requirement for additional funds is known as a margin call. Whilst margin calls induce asymmetry in the returns distribution, there is no chance of an investor losing more than their original stake without further investment. They also change the time-series properties of an investment as an asset that may previously have been well-described by a Brownian motion, and thus memoryless, now becomes a first-hitting process in which once a boundary value has been crossed (the margin requirement) the asset value is fixed at that boundary thereafter. This has the important implication that, given sufficient volatility, the investor can no-longer expect to obtain an average return simply by buying the asset and holding it. Thus, whilst margin trading limits large losses it also reduces the average return as there is an increased probability that the return is zero. In the remainder of this

\footnotetext{
${ }^{6}$ Brokers frequently specify a "maintainance margin" requirement. This is lower than the initial market requirement and prevents traders having to post collateral immediately after opening a position in the event of a small loss.
} 
section we first formalise this intuition about the mean and the skewness of the returns distribution, before outlining the institutional context and the data we use to test our predictions.

\subsection{Margin Trading has a reduced expected return (at any horizon)}

The expected return $E\left[r_{c t}^{x}\right]$ of an asset $x$ with weakly positive returns over a period $t$ where $c$ is the price of $x$ that triggers a margin call is given by:

$$
E\left[r_{c t}^{x}\right]=E\left[r_{t}^{x} \mid x>c\right] \cdot P(x>c)+E\left[r_{t}^{x} \mid x \leq c\right] \cdot(1-P(x>c))
$$

We assume that the mean return on the asset, given a movement that takes it below the margin threshold is negative. A margin call always involves some loss, the exact amount will depend on the degree of leverage and the size of the price movement. Thus, formally, a margin requirement $c$ transforms the stochastic-process describing the evolution of $x$ into a super-martingale and Proposition 2.1 follows immediately. Here, what follows is a heuristic form of this argument to make the intuition clearer.

For our purposes it is sufficient to denote the return given a margin call as $\gamma$. That is, $0>E\left[r_{c t}^{x} \mid x \leq c\right]=\gamma$. Thus, (1) simplifies to:

$$
E\left[r_{c t}^{x}\right]=E\left[r_{t}^{x} \mid x>c\right] \cdot P(x>c)+\gamma
$$

Since the return given a margin requirement is lower when it binds than for the same realisation of $x$ without such a requirement, and the return is the same when it does not bind. It follows that returns are lower in the presence of margin calls. That is, given $\gamma<E\left[r_{t}^{x} \mid x \leq c\right]$ and $E\left[r_{t}^{x} \mid x>c\right]=$ $E\left[r_{c t}^{x} \mid x>c\right]$, it follows $E\left[r_{t c}^{x}\right]<E\left[r_{t}^{x}\right]$. Writing $P(x>c)$ as a first-hitting process with boundary $x_{c}$ gives:

$$
P(x>c)=\left(1-\frac{1}{\sqrt{2 \pi \sigma^{2} t}}\left\{\exp \left(-\frac{\left(x-x_{0}\right)^{2}}{2 \sigma^{2} t}\right)-\exp \left(-\frac{\left(x-\left(x_{0}-2 x_{c}\right)\right)^{2}}{2 \sigma^{2} t}\right)\right\}\right.
$$

The return is then given by:

$$
E\left[r_{c t}^{x}\right]=E\left[x_{t} \mid x_{t}>x_{c}\right] P(x>c)+\gamma[1-P(x>c)]
$$

Note, that we can think about the absence of a margin requirement as either having no impact on the return in which case: $E\left[r_{t}\right]=E\left[x \mid x>x_{c}\right]+E\left[x \mid x \leq x_{c}\right]$ or equivalently that the margin requirement never binds, i.e.: $x_{c}=-\infty$, which implies that $E r_{t}=E[x \mid x>c]=E[x]$. Inspection of 3 shows the probability of the margin requirement being violated is increasing in the volatility $\sigma^{2}$ and the holding 
period $t$. This is natural, as an asset with no volatility would never trigger a margin call. But, this also highlights that if margin requirements are well matched to assets' properties then more volatile assets would be associated with higher margin requirements. Of course, this would reduce the skewness of the returns distribution, and hence the hedonic returns. We shall see in Section 4 that whilst we would expect margin investors to be disproportionately sensitive to volatility, we in fact observe the opposite. We summarise this argument with the following proposition:

Proposition 2.1. The expected return $E\left[r_{c t}^{x}\right]$ of an asset $x$ over a period $t$ with margin requirement $c$ is decreasing in $c$ and always lower than the return in the absence of a margin requirement.

\subsection{Skewness}

The previous section showed the effect of a margin requirement on mean returns. This section will examine the impact on skewness. Barberis (2012) studies how the use of a stopping rule, such as an individual who has lost their gambling money leaving the casino, leads to a skewed-distribution of returns even given binomial gambles. In a financial market there is normally no such stopping rule and an investor may hold a position and thus wait, potentially indefinitely, to obtain the average return. Even if a position is closed it is unlikely to lead to the loss of all of one's funds. Margin trading changes this. The combination of greater leverage and limited liquidity means that the probability at any given horizon of losing the entire initial investment in a portfolio is substantial. We show that the presence of a margin requirement induces right-skewed, 'lottery', returns. To do this we analyse the properties of a truncated normal distribution. By extending the work of Pender (2015), who characterises the moments of a truncated normal distribution using Hermitian polynomials, the following can be shown:

Proposition 2.2. The derivative of the skewness with respect to the lower truncation point $A$ is positive, thus a larger margin requirement increases the skewness of the returns of a given asset $X$

$$
\frac{\partial S k e w_{X}}{\partial A} \equiv \frac{\partial E\left[\left(x-\mu_{x}\right)^{3}\right]}{\partial A}>0
$$

Proof. See Appendix B for proof.

It is important to note that the above result is dependent on the underlying distribution. For example, truncation does not necessarily result in skewness in a Pareto distribution. However, as we will show later, raw returns for the market we consider follow a normal distribution. 


\subsection{Context and Data}

Before moving to the empirical evidence we first outline the salient features of the Rebar futures market that is this paper's focus. Rebar are aluminium bars mainly used in construction. China is the largest market for Rebar, by volume, and has been for over 20 years. In order to manage risk and provide for the hedging of exposure to the Rebar market, Rebar futures contracts were introduced on the 27/03/2009 in the Shanghai Futures Exchange (SHFE). Since then, Rebar futures contracts have become one of the most actively traded commodity futures in Chinese financial markets. At the same time, the Rebar futures market has become the biggest metallic futures market in the world based on trading volumes and turnover.

Rebar futures are similar to other commodity futures. There are 12 Rebar futures contract delivery dates each year. Each contract is deliverable in the middle of the month and starts trading 12 months earlier. For instance, RB1210 (RB is the initial commodity code of Rebar futures) specifies the Rebar futures contract which started trading in the middle of October in 2011 and delivered in the middle of October in 2012. Excluding holidays and weekends, the number of trading days for each contract is approximately 230. Daily trading time, as set by SHFE is 3.75 hours per day (3.58 hours before $27 / 06 / 2010$ ). Price changes on the SHFE are limited to a maximum of $7 \%$ per day. If these limits are met, the market is closed until the next trading day.

Chinese futures can be traded by anyone willing to open an account with one of the, at the time of writing, 198 registered Chinese futures companies (henceforth, brokerages). After opening and funding a margin account, individuals may trade any exchange traded futures in Chinese markets. During the period covered by our data, these brokerages did not function as market makers: Their sole role was to execute their clients' orders on the relevant Chinese futures exchanges. Orders may be submitted by customers through telephone or computer; the brokerage then submits orders to exchanges by computer only, and thus precise timings are recorded of when orders are submitted and fulfilled.

The SHFE has strict rules that only registered institutional traders can take delivery of commodities. Individual traders, who still hold open positions one month before delivery have their positions liquidated. ${ }^{7}$

Rebar futures are traded such that, the trading unit 'one hand' is equal to 10 tons of Rebar. SHFE set the margin ratio based on market conditions. During the period studied, the transaction fee for Rebar futures is between $0.007 \%$ and $0.03 \%$. The minimum margin ratio imposed by the SHFE is

\footnotetext{
${ }^{7}$ Registered institutional traders must own production capacity or a storage warehouse to be eligible to take delivery. The Chinese Securities Regulatory Commission (CSRC) checks these requirements are met in order to protect both trading parties.
} 
varied between $5 \%$ and $12 \%$, although it is $7 \%$ for almost the whole period we study. Brokerages also set a further margin ratio, which is generally $4 \%-5 \%$ higher than the margin ratio of the SHFE. This is designed to protect traders from mandatory liquidation. Based on these two margin ratios traders have two margin requirement "deadlines". Assuming a trader has open positions, they must ensure sufficient funds are in their margin account, as given by the Brokerage's margin ratio. When the money in a trader's account is lower than the margin requirement of the brokerage, the brokerage gives the trader a margin call in order to provide them the opportunity to add additional funds as collateral. If the trader does not deposit funds into their margin account and further losses are incurred such that the lower margin requirement of SHFE is violated, then the SHFE will liquidate all positions of the trader.

Our data are provided by one of the 198 brokerage firms. They cover the period 27th March 2009 to 30th of September 2013 (50 contracts). During this period we observe the exact trading history for all of the 22,411 clients of this brokerage firm. That is, for a given client, we observe each order submitted (for Rebar), its form (limit or market), size, price, and the precise time it was submitted. Further we observe the precise details of how, when and if the order was fulfilled. Further, we also observe the state of every trader's margin account including any daily gains or losses from trading, including from other assets, and any funds added or withdrawn from the account.

Whilst impossible to verify, there is reason to believe that the individuals who use the brokerage we study are representative of market participants as a whole. The fee structure and margin requirements of competing firms are comparable to the firm we study. The only noteworthy feature is that our firm is amongst the largest. Finally, it is worth noting that our data start on the same day as Rebar are first traded on the SHFE thus ensuring that we can be confident that none of our results are unique to some sub-period of Rebar trading history.

\subsection{Skewness}

We analyse the quantitative effects of margin trading on the distribution of returns. As noted above a key feature of the SHFE is that market movements are limited to $\pm 7 \%$ a day. If these limits are reached then trading is suspended. This means that whilst the magnitude of the upside return is limited on any given day by reinvesting the original gains plus or minus any losses on subsequent days, we will observe the familiar lottery-type returns pattern. Losses are always truncated to be at most the original stake, whilst gains are unbounded. This complicates an analytical extension of Barberis (2012) and we therefore analyse numerically how the existence of a margin call skews individual returns given the empirical asset returns distribution. The results suggest that although 
these distributions of single-period asset returns are approximately normal, that distribution of individual returns taking into account the margin requirement are highly skewed. Indeed the key quantitative and qualitative feature of the simulated returns data is the relationship between skewness and margin calls.

We estimate a $\operatorname{GARCH}(1,1)$ ARIMA $(1,1,0)$ model based on Rebar future prices for the entire period covered by our data March 2009 to September 2013. In order to treat long and short positions equally we set the drift term equal to zero. Using this model, we simulate 5 million independent twenty-one day price paths. For each path we calculate the returns of traders. If traders' positions lose money such that they violate their margin requirement they reduce their positions by the minimum amount such that this is no longer the case. We contrast the returns of margin traders with those of a trader holding the asset without leverage. For margin traders, we calculated results for long and short positions and for different numbers of initial contracts. In line with market rules, the margin requirement is set to $7 \%$ and the maximum price change on any day is $7 \%{ }^{8}$ Each contract is for 10 hands of Rebar and the initial price for each hand is RMB3000. Traders start the simulation with initial wealth equal to $15 \%$ of the contract value.

Panels $2 \mathrm{~b}$ and $2 \mathrm{a}$ of Figure 2 show the simulated returns distribution of traders. The left hand figure illustrates the case of traders with a single long futures contract, whilst the right hand figure shows the distribution for a trader who initially holds 5 contracts. We first consider the case with traders with a single long or single short contract. The average return for an nonleveraged trader over the period is 0 whilst the leveraged trader's returns are approximately $-1 \%$. Importantly, regardless of whether a trader takes a long or short position the margin account results in negative returns, and in both cases, by the end of the simulation, approximately $88 \%$ of traders have incurred sufficient losses that they can no longer meet their margin requirements and so have no futures contracts. Both distributions have a negative mean and are heavily skewed, as predicted by Propositions 2.1 and 2.2 respectively. The lower skewness for the larger initial position reflects that individuals faced with a margin call may close one or more open positions and continue to hold the remainder of their portfolio. As we will see below, most of the investors we study open one position at a time.

\subsection{Losses}

The model described in the last section predicted that on average traders subject to margin requirements lose money. In this section we use individual account histories of futures traders

\footnotetext{
${ }^{8}$ Whilst the brokers' requirement is $12 \%$, this is understood to often be negotiable; thus, assuming only the SHFE required margin represents the minimum chance of margin calls, and thus the least skewed distribution.
} 


\section{Session}

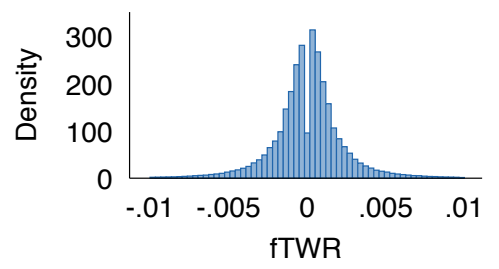

3 Days

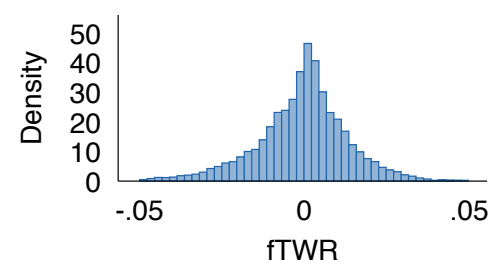

6 Days

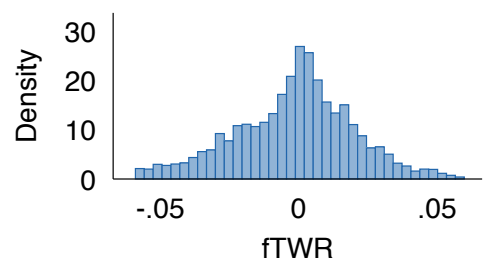

1 Day

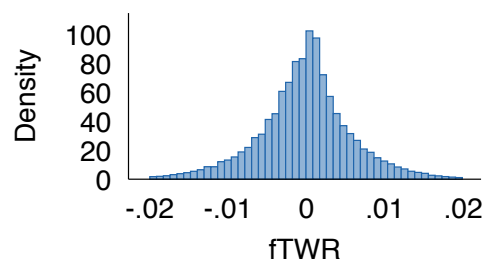

4 Days

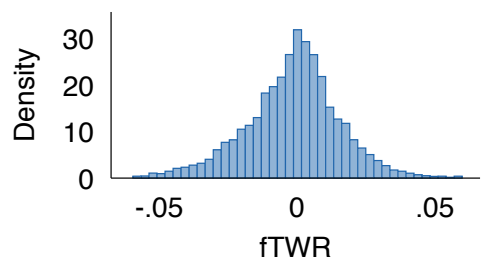

7 Days

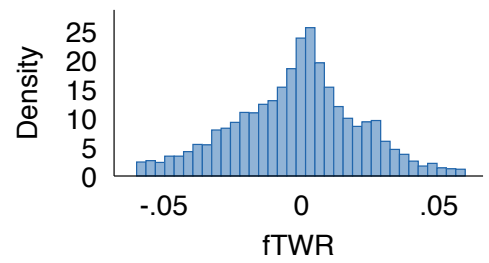

2 Days

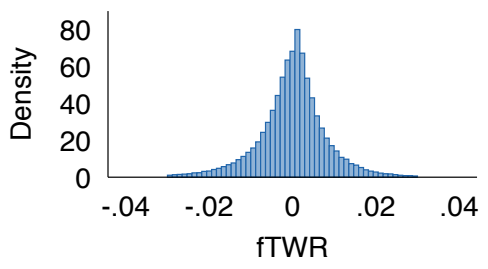

5 Days

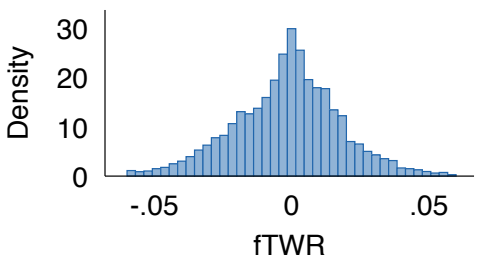

8 Days

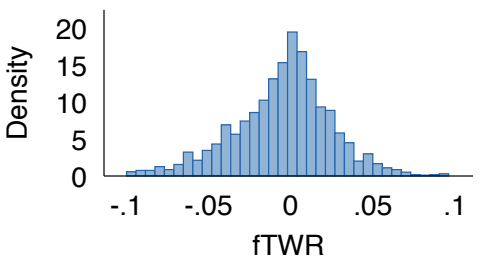

Each graph shows the distribution of returns for positions held for a specified length. $f T W R$ is the absolute return of each position for a given maximum length, weighted by its size. The top left histogram shows the sizeweighted distribution of returns for positions held for one trading session or less. The eight remaining plots are analogous for longer holding periods. The distribution is truncated for clarity at \pm 0.01 for Sessional returns, and $\pm\{0.02,0.03,0.05,0.06,0.06,0.06,0.06,0.1\}$ for the 1-Day, 2-Day returns, etc.

Figure 2: Simulated Returns from Margin Trading

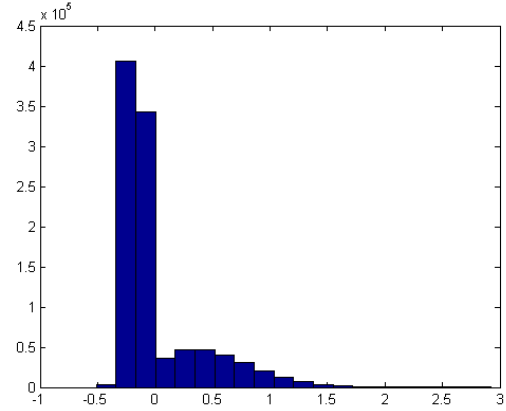

(a) Initial Position of 1 Contract

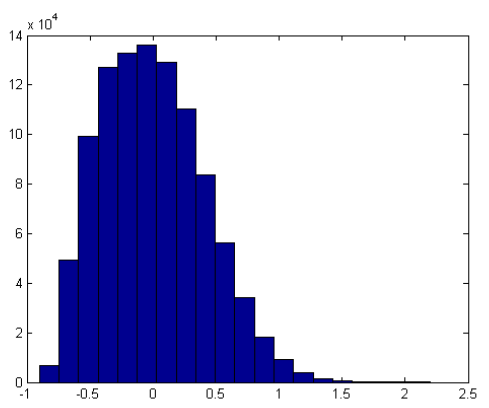

(b) Initial Position of 5 Contracts

Results are the simulated absolute returns of traders with an initial position of 1 contract and 5 contracts respectively, and wealth of $15 \%$ of the value of these positions over 21 trading days. This is equivalent to RMB 4,500 and 22,500 respectively. Traders are assumed to partially close positions in response to margin calls and to use any profits to open additional positions. The simulated distribution of prices is estimated using a $\operatorname{GARCH}(1,1) \operatorname{ARIMA}(1,1,0)$ model for the Rebar future price for the entire period covered by our data March 2009 to September 2013. In order to treat long and short positions equally the drift term is set equal to zero. 
to show that most traders lose money at at least the predicted rate. We first consider the overall distribution of average-daily returns, and then provide evidence for the margin-call as the source of lower returns and excess positive-skew by analysing the distribution of returns, per position.

The traders in our data do not trade every day and often go months without trading or having open positions. It is appropriate therefore, and will be useful when we consider the position returns, to treat these episodes as separate. We split the trader's trading history into a set of mutually exclusive sub-periods using a clustering algorithm described in Appendix D.

Figure 3 shows traders' average daily returns in each of the sub-periods. Both panels present kernel density plots, truncated for clarity. Panel 3a limits the returns to between $-2 \%$ and $5 \%$ and Panel $3 \mathrm{~b}$ to between $0.2 \%$ and $0.5 \%$. In both cases the dashed vertical line describes the mean daily return of $-0.123 \%$, equivalent to an annualised return of $-27 \% .{ }^{9}$ Put differently, this distribution implies that $88 \%$ of traders will lose money on an average day and, conditional on losing, their average return will be $-0.274 \%$. The large difference in the conditional and unconditional return is suggestive of the positive skew in the data. This skewness can be seen in both Panel 3a and more easily in the truncated distribution in Panel 3b. ${ }^{10}$ Inspection of Panel $3 \mathrm{~b}$ makes plain the positive skew in the distribution of returns. Comparing the distribution either side of the mean line shows that whilst losses are clustered near the mean, the positive returns are much more dispersed. Measured numerically, the skewness is 5.69; this is greater than in the numerical analysis where it is 1.4. Whilst, the calibration is deliberately simple and we have not attempted a close fit to the empirical data this discrepancy likely reflects additional, non-modelled, sources of variation in the empirical data such as trading frequency, and willingness to re-invest.

The implication of Figure 3 is clear: the margin traders we study almost all obtain returns substantially worse than 0 . Given that traders may take a long or a short position, the negative price trend over the period we study cannot be the cause. Notably, traders open an almost identical number of long and short positions (50.5\% long). Figure A1 plots the returns for all positions taken in our data. The data are approximately-normally distributed whilst the mean is positive. Although surprising this effect is due to a small number of extremely profitable positions taken which are discussed in detail later in the paper. There is some evidence of skewness, which is unsurprising given that many of the positions taken will be incompletely underwritten. ${ }^{11}$

\footnotetext{
${ }^{9}$ This figure is based on a trading year of 250 days.

${ }^{10}$ Our preferred measure excludes sub-periods for which there is less than 10 days of trading activity. This is to ensure our results are not driven by new traders who may not understand the market, or who only trade once or twice before exiting the market. All of our results are robust to this choice and a comparison is reported in Figure A5 in the Appendix.

${ }^{11}$ Note, however, that if an individual is willing to provide additional capital when faced with a margin call then we will not observe either the reduced returns or the additional skew. This is because, in effect, the individual is not leveraged. In reality few individuals will be willing to fully underwrite their trading, and so we should expect a different returns distribution before and after they have committed all of the funds they are willing or able to commit. It is further likely
} 
To demonstrate that it is the return distribution of leveraged traders that induces the skewness, we now seek to identify those most likely to not be in a position to underwrite their trades. To do so we treat the amount an individual is willing to commit to trading as being fixed in each sub-period of trading. We then treat the amount an individual is willing to invest in a given subperiod as a strictly increasing function of the amount invested and any profits, in that sub-period, to date. That is, even if they withdraw money from their trading account we assume that they will be willing to re-deposit those funds in the current sub-period. This definition of constrained traders is conservative in that it will classify some unconstrained traders as constrained. To see this, consider that some of the traders who have withdrawn money may have used it for other purposes and so not be able to reinvest it. Thus, constrained traders are those for whom the maximum committed funds has already been reached, and whom have insufficient funds in their brokerage account to open additional positions. The length-distribution of these sub-periods is described in Figure A6 in the Appendix; but, as discussed in detail below, the average position is relatively small and held for under a day. Such relatively frequent, high-cost trading has previously been documented as a key reason why retail investors often fare badly (see, Barber and Odean, 2000, Barber et al., 2009). Figure A2 thus compares the returns for constrained and non-constrained investors after trading costs.

Comparison of the red line, describing the traders more likely to be constrained, and the blue line, those more likely to be unconstrained, makes clear the effect of margin trading. The constrained traders earn lower returns but have more skewness in their returns as our theory and analysis predicts. That the distribution for the unconstrained investors is not more different likely reflects noise, and our imperfect proxy for who is constrained. Comparison of the returns with and without trading costs in Figures A3 and A4 also suggest that the regular trading induces substantial changes in the distribution of returns, making identifying the differences yet more difficult. It is nonetheless clear that that being more likely to be leveraged is associated with a substantial increase in skewness, and a reduction in the average return.

\section{Margin Trading and the Optimal Portfolio}

The previous section showed that traders were making negative returns from their Rebar investments. One explanation for this is that they are using Rebar futures to hedge other risks. This section considers, and dismisses, the possibility that traders could be investing in Rebar at a loss as

that the total funds individuals are willing to commit to trading will vary over time. Of course, how much additional money an individual is willing to commit is unobservable as is its change. 
Figure 3: Average Daily Returns Including Transaction Costs

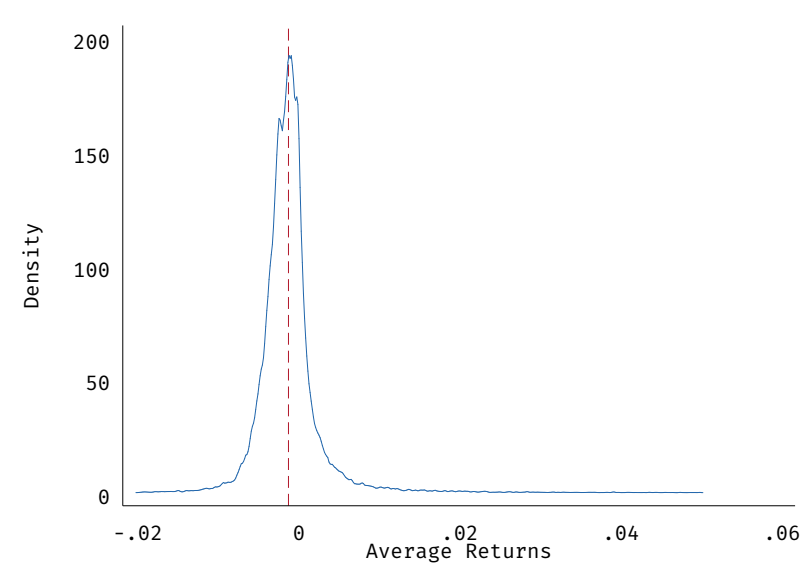

(a)

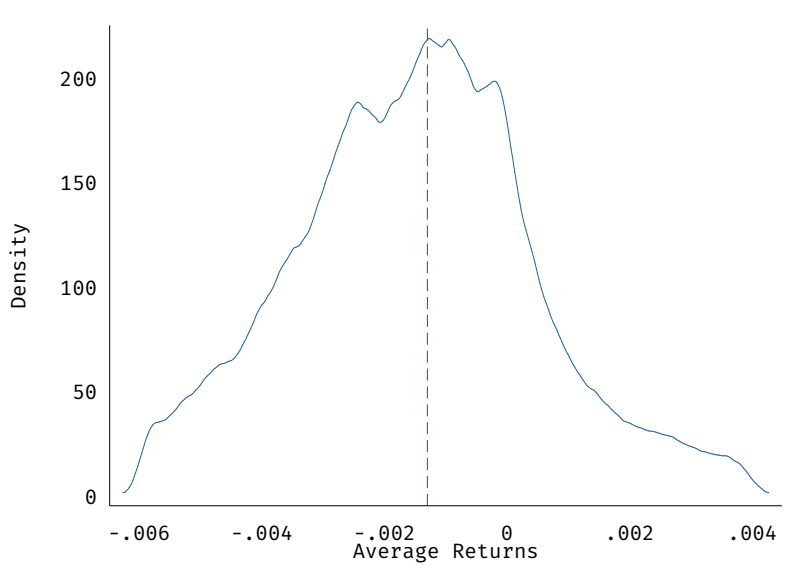

(b)

Average returns are calculated based on the absolute return over the duration of the positions held that day. Returns include the observed trading costs which vary between $0.0068 \%$ and $0.03 \%$. As described in Section 4.3 a small fraction of traders achieve large returns: but, the reported distributions are truncated for clarity at -0.02 and 0.05 and -0.006 and 0.004 for the left and right panels, respectively. The red dashed vertical line is the mean daily return.

part of managing a long-term portfolio. In its simplest form such an argument is a claim that, whilst investing in Rebar on the margin may have a negative return, it would allow investors to achieve a sufficient reduction in the variance of their portfolio returns to be worthwhile. We take this claim seriously and outline how it may be possible in theory but impossible in practice.

We first show that it is essentially impossible for Rebar to be used to hedge risk efficiently. For any feasible asset, it is shown that the investor would be better taking a combination of the asset and cash, paying a return of zero, than a portfolio including Rebar.

We consider two assets, $a$ and $b$, with returns $r_{a}$ and $r_{b}$ that are normally distributed with standard deviations $\sigma_{a}$ and $\sigma_{b}$ respectively. The portfolio comprising these two assets with weight $w$ of asset $a$ has return $r$ :

$$
r=w r_{a}+(1-w) r_{b}
$$

And variance:

$$
\sigma^{2}=w^{2} \sigma_{a}^{2}+(1-w)^{2} \sigma_{b}^{2}+2 \rho w(1-w) \sigma_{a} \sigma_{b}
$$

Where $\rho$ is the covariance of assets $a$ and $b$. The range of possible portfolio returns and standard deviations is shown in Figure 5. Rearranging and solving for $r$ gives: 
Figure 4: Average Daily Returns for Constrained and Unconstrained Traders
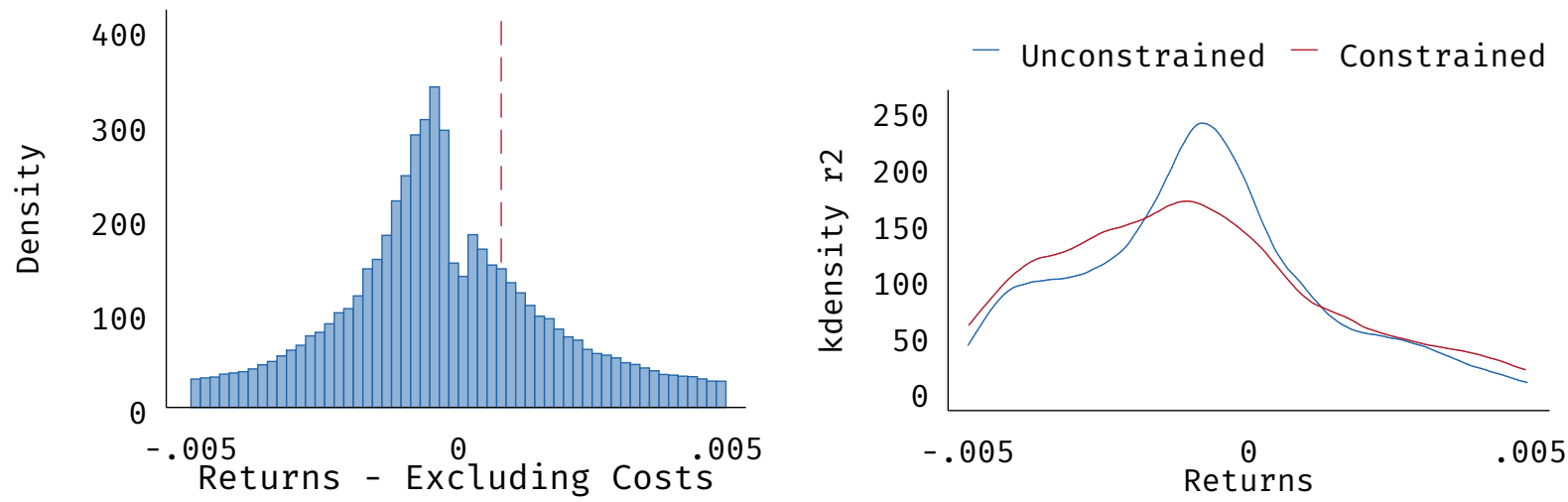

Unconstrained Excluding Costs

Returns Incuding Costs
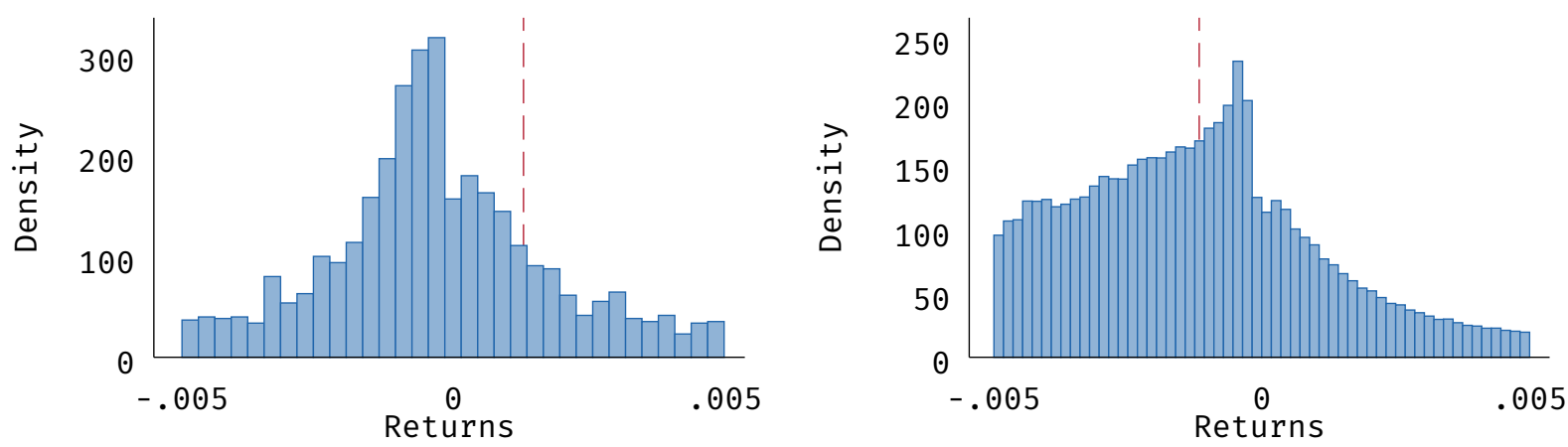

The figures describe the difference in the absolute returns obtained by constrained - those traders identified as having no additional investable funds - and unconstrained traders - those able to meet a margin call with additional funds, before and after trading costs are taken into account. The top left histogram plots the distribution in absolute average daily returns excluding transaction costs for all traders. The red dashed vertical line is the mean daily return, as it is below. The top right figure plots two kernel density plots showing the difference in the distribution of returns obtained by constrained and unconstrained traders. The lower left figure plots the distribution of returns obtained by unconstrained traders before trading costs. The bottom right histogram describes the distribution of average daily returns after costs for all traders. All distributions are truncated at -0.005 and 0.005 for clarity. 
Figure 5: Optimal Portfolio Frontier

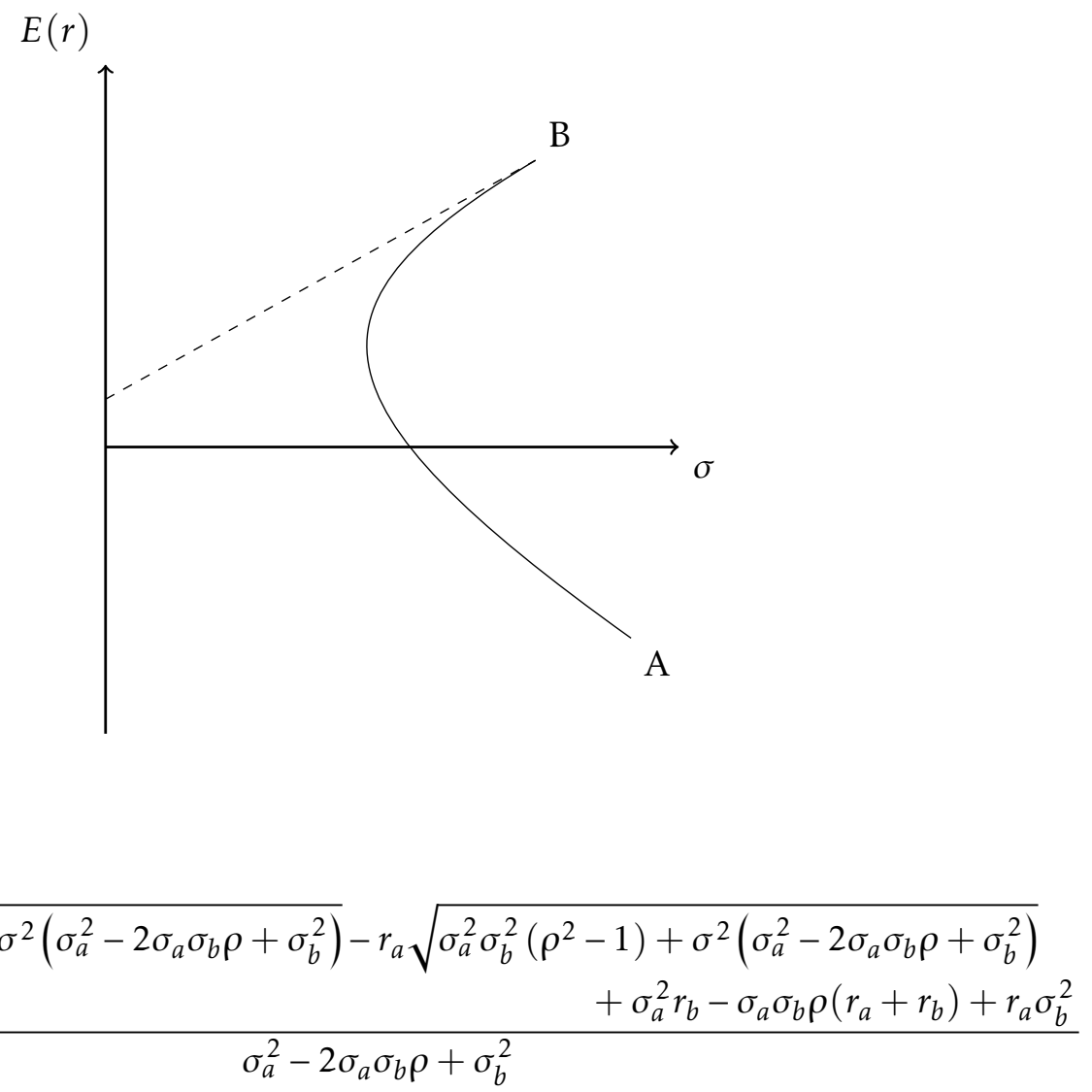

Equation 8 describes the typical risk return trade-off for a portfolio. We refer to the asset with lower return, corresponding to Rebar, as asset A, and the asset with higher return corresponding to another asset, or portfolio of assets, as B. To demonstrate that Rebar never appears in an optimal portfolio, we show that for all portfolio's a higher expected return, for a given level of variance, may be obtained by taking a combination of asset $\mathrm{B}$ and the riskless asset than by including Rebar.

We note that, unlike standard portfolio theory, taking a short position in Rebar does not extend the efficient frontier beyond asset B. The negative return of Rebar comes from margin trading and not from the asset itself - therefore, taking a short position in Rebar does not result in a positive return. Whilst Rebar may provide diversification benefits, it has such a high negative return that it never increases expected returns. The highest expected return is, therefore, found in the portfolio solely consisting of B.

In order to demonstrate that the diversification benefit of Rebar is outweighed by its negative expected return it is shown that the efficient frontier is always dominated by the return that may be obtained from taking an appropriate portfolio of asset B and the riskless asset. In other words the efficient frontier always lies below the straight line connecting the risk-free rate and asset $\mathrm{B}$. To do this it is sufficient to prove that the derivative of the efficient frontier at Asset B is less than that of the straight-line representing portfolios composed of a mixture of asset B and a riskless asset. This is 
because the second derivative of the risk-return curve is negative in the upper portion; therefore, if the condition is met, the efficient frontier will always be below the straight line.

The return at point $\mathrm{B}$ is dependent on the identify and characteristics of asset B. For assets with higher returns, the straight line becomes progressively steeper, individuals will rationally be willing to sacrifice ever more return for a given reduction in variance. Thus, at some point, given $-1<\rho<1$ the optimal portfolio will include some Rebar. However, we show that this will only be the case given annualised returns of Rebar of -0.27 , with a standard deviation of 0.13 and a correlation of $-0.15^{12}$, and for assets with returns far in excess of those realistically observable. In particular, it is not true if assets have returns less than $1000 \%$. In particular, setting:

$$
\frac{\partial r}{\partial \sigma}=\frac{s\left(r_{b}-r_{a}\right)}{\sqrt{\sigma_{a}^{2} \sigma_{b}^{2}\left(\rho^{2}-1\right)+\sigma^{2}\left(\sigma_{a}^{2}-2 \sigma_{a} \sigma_{b} \rho+\sigma_{b}^{2}\right)}}
$$

Then it may be verified that if $r_{a}=-0.27, \sigma_{a}=0.13,0 \leq w \leq 1, \sigma_{b}>0,-1<\rho<1$, and $r_{b}>0$ then no point exists such that:

$$
\frac{s\left(r_{b}-r_{a}\right)}{\sqrt{\sigma_{a}^{2} \sigma_{b}^{2}\left(\rho^{2}-1\right)+\sigma^{2}\left(\sigma_{a}^{2}-2 \sigma_{a} \sigma_{b} \rho+\sigma_{b}^{2}\right)}}-\frac{r_{b}}{\sigma_{b}}<0
$$

If $0<r_{b} \leq 1000$ and $\sigma_{b}=0.13$ (equal to that of Rebar). Note that this range may be much larger; but, given no asset normally exists with a Sharpe ratio near to $\frac{r_{b}}{\sigma_{b}}=\frac{1000}{0.13}$ there is no need to look further.

In support of this argument, in the Appendix, we demonstrate that Rebar does not ever appear in the optimal portfolio given the assets available to Chinese investors during the period. We find no evidence that an optimal portfolio, of any size, would contain leveraged Rebar investments.

In the next section, we also show that the modal position is opened for less than a day. Such frequent trading is incompatible with an explanation of portfolio optimisation given that traders face substantial trading costs. Thus, we can see that a portfolio explanation is not only unlikely in theory, it is rejected by the data.

\section{Behaviour}

Margin Trading reduces expected returns and is associated with a high chance of a complete loss of the initial investment. Nor are such investments ever part of an optimal portfolio. This section provides evidence that observed behaviour is consistent with hedonic or gambling-type motivations.

\footnotetext{
${ }^{12}$ This correlation is the largest negative correlation between Rebar and any of 9000 other Chinese assets.
} 
We show that traders open their positions only briefly, but too often, and that they do not exploit arbitrage opportunities. Moreover, we show that the average trader is heavily liquidity constrained and that almost all trade is focused on three out of twelve contracts. We begin by analysing the properties of Rebar Futures and then the behaviour of individual investors.

\subsection{Aggregate Behaviour}

Figure 6 describes the market properties of Rebar. We focus on 2012 for clarity, but the conclusions are the same for other years in our sample. ${ }^{13}$ Panel 6 a describes the prices of the 12 contracts traded during 2012. The thick blue line is the average of the Tianjin and Shanghai spot prices. ${ }^{14}$ It can be sees that whilst the individual future prices tend to be relatively similar, albeit with important exceptions, they are often quite different from the spot price, indicating the possibility of arbitrage profits. We formally show and discuss this possibility below.

Panel $6 \mathrm{~b}$ describes a very important feature of the market - almost all of the trading volume is concentrated on three contracts: January, March, and October. Moreover, one contract is traded almost exclusively at any one time. Specifically, the most heavily traded contract on any given day accounted for 95\% of daily volume in 2011 rising to over 98\% of the volume in $2013 .{ }^{15}$ Panel A9c shows the total market position by contract which makes clear that not only are only three contracts being traded but positions are only being opened in these three contracts. ${ }^{16}$ Why trading is concentrated on these three contracts in particular is unclear but does not seem to have any substantive economic basis. Figure A12 in the Appendix reports net Chinese imports of Steel, and Rebar specifically, by month. It also reports the sales of one of the largest domestic Steel manufacturers. ${ }^{17}$ It is clear that whilst there is some seasonal fluctuation - imports are lower in the first few months, perhaps due to Chinese New Year and cold winter weather prohibiting building - there is no reason in the sales data for traders' exclusive focus on January, March, and October. Notably, there is almost no activity in the other contracts. If trading is seen as gambling then the focus on one of three contracts at any given time is rationalisable, and informally can be seen to reflect a co-ordination equilibrium. Every additional trader on a given contract increases market activity, and incorporates a wider range of beliefs about the future. As a result prices, change more rapidly, meaning that even if traders open positions for relatively short periods of time, there is sufficient

\footnotetext{
${ }^{13}$ Figures A9 - A11 in the Appendix reproduce Figure 6 for the other years in our sample.

${ }^{14}$ Unsurprisingly, given the distances and transaction costs involved, the two are related but not identical, as can be seen in Figure A13 in the Appendix.

${ }^{15}$ Figure A7 which is a stacked bar chart showing the composition of total trading volumes over time makes this same point graphically - almost all of the volume is accounted for by one of these three contracts at any point throughout the whole period.

${ }^{16}$ All twelve contracts are plotted; but, the other nine are indistinguishable from the $x$-axis.

${ }^{17}$ We are unable to name this firm for confidentiality reasons.
} 
price variation and the chance of substantial positive movements that would provide greater hedonic returns. The benefits conferred by each additional trader are enjoyed by all other traders, and these economies of scale lead to a single contract being traded at a time, even if the choice of which is largely arbitrary. Whilst, hedgers would also potentially gain benefits from the larger numbers of traders in terms of potentially higher liquidity the confinement of trade to three contracts creates significant basis risk. Given that there is no plausible use of steel that only takes place in omly three months of the year, and it is costly and bulky to store, then any hedging strategy should involve all twelve contracts in at least some proportion. This is, therefore, evidence that these traders are not opening positions to hedge their exposure to aluminium price changes.

Panel $6 \mathrm{~d}$ shows that there is considerable variation in volatility over time. Comparison with Panel $6 \mathrm{~b}$ suggests that this is related to the volume of trading, again consistent with the 'trading as gambling' hypothesis. ${ }^{18}$ Note, however, that, as the correlations discussed below show, whilst there is also volatility in the Rebar spot-price, this does not predict all of the volatility observed in the Futures prices. If we consider the full sample of volatility reported in Figure A14 in the Appendix, then the lack of any obvious pattern becomes clearer still. It is difficult to make arguments about causality; but, it is plausible that it runs from both volume to volatility and vice-versa, with additional volatility attracting more traders to gamble on the more frequent price movements. At the same time more traders with little information could potentially increase volatility.

One interesting consequence of the focus of trading activity on these three contracts is it seems to have had no impact on the efficiency of the market. If markets were efficient then both the correlation between the change in the (log of) the spot price $\Delta \log \left(s_{t}\right)$ and the change in the $(\log$ of) the future price, $\Delta \log \left(f_{t}\right)$ should be close to unity. In fact, as reported by Table 2 they are always substantially lower. Cointegration-based tests of market-efficiency, allowing for risk-aversion or riskloving (see, Chowdhury, 1991), tell the same story and are reported in Table 3. This may reflect the practical difficulties involved in Rebar arbitrage; the Rebar are bulky and there are restrictions on whom may take delivery. But, these difficulties should be far from insurmountable. Rebar are not perishable and are easily saleable and so it is perhaps surprising that no arbitrageur owning production or storage capacity has emerged. Of course, if as conjectured the futures market is largely comprised of speculators, then there is less reason to believe that there should be an equilibrium relationship between the spot and forward price. This itself may place limits on arbitrage as argued by Shleifer and Vishny (1997), making the costs associated with possessing the physical infrastructure prohibitive.

\footnotetext{
${ }^{18}$ A simple two-way fixed effects regression of Volatility $_{i t}=\beta$ Volume $i t+\alpha_{i}+\gamma_{t}+\epsilon_{i t}$ suggests that a one standard deviation increase in Volume leads to a $0.08 \%$ standard deviation or 3 percentage point increase in Volatility.
} 
Figure 6: 2012 Rebar Contracts

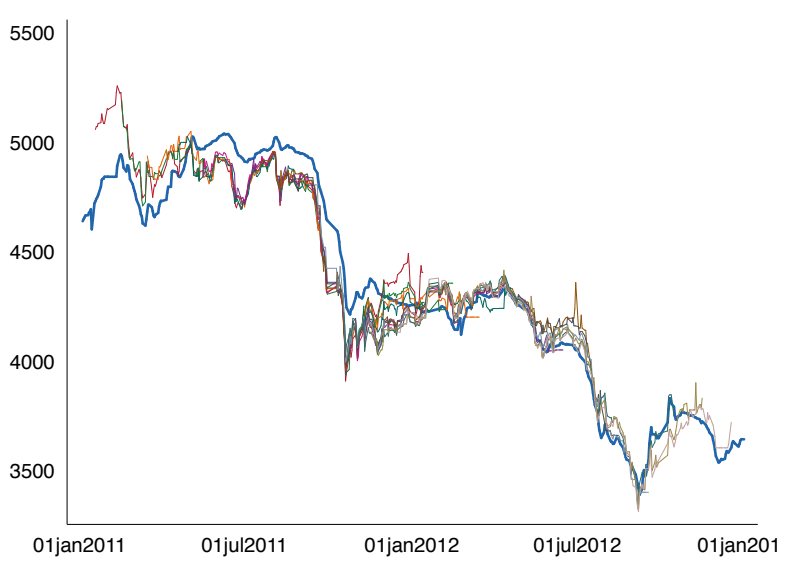

(a) Price

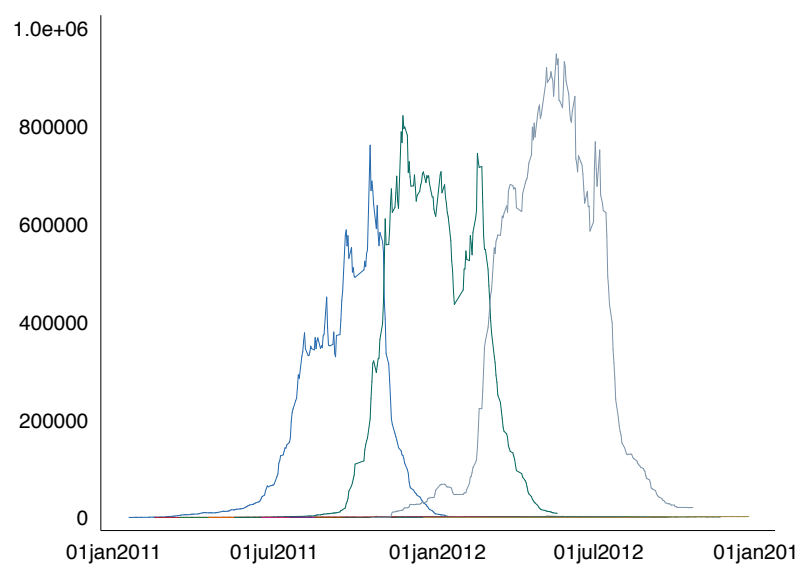

(c) Market Position

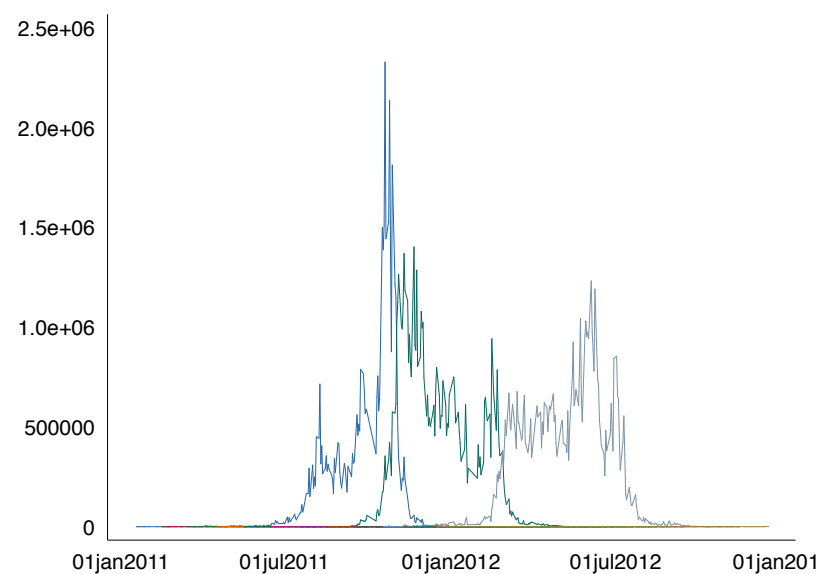

(b) Volume

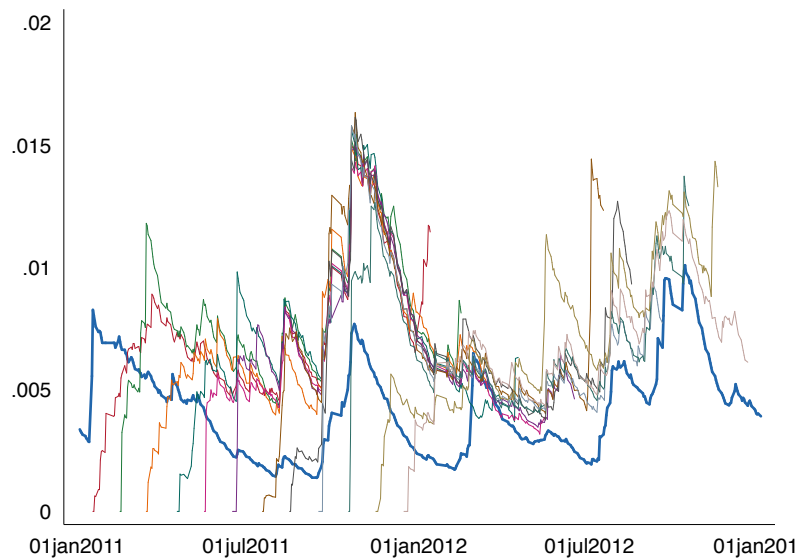

(d) Volatility

Figures describe Price (in RMB), Volume (Contracts), Net Market Position (Open Interest), Volatility (Exponential Moving Average of the Variance of the Log Return $\lambda=0.94$ ) of contracts RB1201-RB1212; that is, contracts for delivery in 2012. In Figure $6 \mathrm{a}$, the thick blue line is the volume weighted average of the price of all 12 contracts. Figure $6 \mathrm{~b}$ reflects that only three contracts have any substantial volume of trades, as does $6 \mathrm{c}$. The thick blue line in panel $6 \mathrm{~d}$ shows the average price volatility of all contracts. 


\subsection{Traders Open Positions Briefly Too Often}

If the traders we study are trading as as a form of recreation then we should expect to observe behaviour consistent with this. In particular, assuming that our Traders are not all night-workers, then we should expect them to have limited time in the day to trade around other tasks. Whereas, if it were the trader's principle occupation then they should have more time available. Figure 7 provides evidence that this is the case. In panel 7a we can see that almost all positions are held for less than a day. This is consistent with a trader only being able to manage their position in a short period during the day, on say their lunch break, and thus being concerned about large moves in the price when they are away. It may also be the case that investors derive higher hedonic returns when they observe price fluctuations compared to making the same investment, but not being able to monitor price changes.

Panel $7 \mathrm{~b}$ describes the distribution of how long traders spend in the market. That is the length of time between their first and their last trade of the day. Traders who only make one trade are treated as being in the market until the end of that session. ${ }^{19}$ Of course, we can not rule out that they are closely monitoring the market for the remainder of the time; but, this does not seem consistent with the other evidence. We see that the average trader is in the market for around one and a half hours a day. Moreover, we see that very few traders trade for more than two hours. In contrast the markets were open for nearly 4 hours each day. It would be expected that professional day-traders would be in the market for times closer to this upper limit rather than the observed median; however, there are very few observations in this area.

Opening positions for only a couple of hours is an example of behaviour that is not consistent with trading for profit (see, Barber and Odean, 2000); but, is consistent with hedonic motivations (see, Dorn and Sengmueller, 2009). Traders will incur fees that are large in comparison with the standard-deviation of prices over the position duration, thereby reducing further - as seen above the poor returns offered by margin trading. This is exacerbated, as discussed below, by the small size of the average position opened. Most often, this is just one contract. As shown in Figure A15 in the Appendix these contracts are also almost exclusively limit orders, but most of these limit orders are marketable. The fact that these traders are mostly not providing liquidity is in contrast to the the positive effects of margin traders proposed in Brunnermeier and Pedersen (2009) and for which Kahraman and Tookes (2013) find evidence for Indian financial markets. The finding of Kahraman and Tookes (2013), that the introduction of margin trading in a market leads to significant increases in market liquidity, are not found in the SHFE context.

\footnotetext{
${ }^{19}$ This assumption is unimportant for the results.
} 
(a) Most Positions Are Closed Within a Day

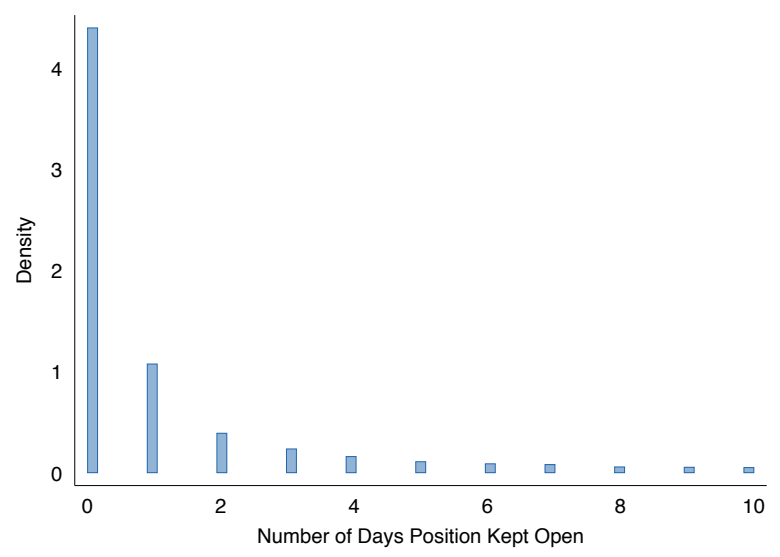

(b) Average Traders Spend Around 11/2Hours Trading A Day

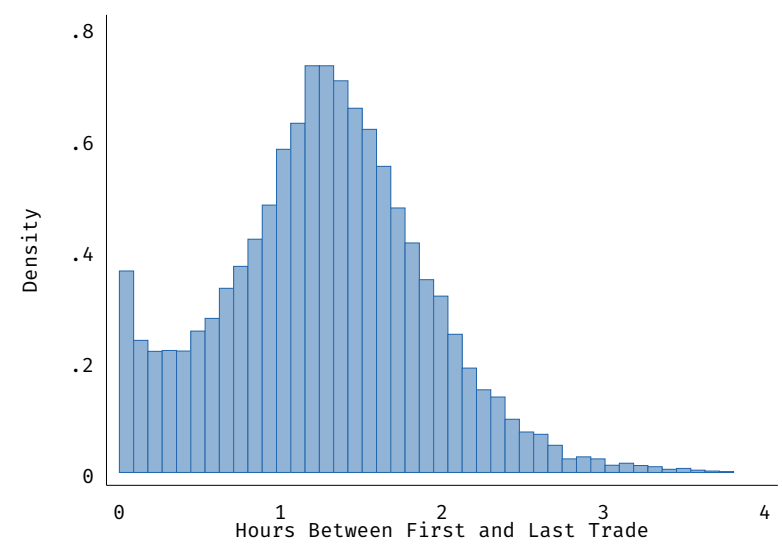

Figure 7a:A position is closed within the day if the trader both begins and ends the day with no open positions. A position being open for two days implies that there are two days (in which the market is open) between the trader opening their position and closing it. Figure 7b: The dependent variable is the number of hours (or fraction thereof) between a trader's first submitted order and their last submitted order. The relatively few traders who submit only one order on a day are treated as being in the market until the end of the session.

\subsection{Small Fraction of Traders Make Huge Profits.}

By no means do all traders lose money. In particular there are a small number of traders who enjoy very substantial profits. Whilst, this is likely to partly reflect good luck, it may also reflect differences in behaviour. Table 1 shows that one key way in which they differ is that the most successful traders maintain their positions for much longer. For the most successful $0.01 \%$ the average is a week compared to less than a day for the modal trader. If instead the top $1 \%$ are considered, the average positions are still held for substantially longer than their less successful peers. These longer holding periods may be a consequence of success as well as a cause. Given the scale of these traders' profits they are often in a position to fully underwrite their positions, allowing them to enjoy a higher average return than their leveraged peers.

The second key difference is described in the next panel of Table 1. The most successful traders trade very frequently, with 400 trades a day not being uncommon. This again may reflect affluence, perhaps itself caused by their success, but it might also suggest a form of algorithmic trading. The heaviest traders execute over 3000 trades a day or one every 5 seconds. Alternatively, it might be one account being operated by a number of individuals concurrently. ${ }^{20}$ One thing that is clear is that these traders are not operating as market-maker. Like all of the traders in our data, they almost exclusively use marketable limit orders, and the fees they pay mean that such market making

\footnotetext{
${ }^{20}$ All of the results in the paper are robust to excluding this tiny number of (very profitable) accounts. That they are unimprtant for the results of this section can be verified by comparing the $90^{\text {th }}$ percentile of the top $1 \%$ of traders in Table 1 with all other traders. In general, excluding these traders strengthens our findings.
} 
would not be profitable. An alternative interpretation of this combination of high trade volumes and long-held position is that the most successful traders are those who place large bets on the trend rather than the high-frequency fluctuations. These traders would thus be making many trades which increase the size of their position and then holding in the hope of a price change. This strategy is clearly more feasible for very liquid traders and thus is not an option for most market participants. This is consistent with the bottom panel of Table 1 which shows that the average trade is also $3-5$ times larger.

Table 1: Trading Behaviour of the most successful traders

\begin{tabular}{|c|c|c|c|c|c|}
\hline Variable & Obs & Mean & Std. Dev. & P90 & P99 \\
\hline \multicolumn{6}{|c|}{ Average Holding Period } \\
\hline Top $0.01 \%$ & 9 & 8.4 & 6.0 & 19.1 & 19.1 \\
\hline Top $0.1 \%$ & 22 & 6.4 & 6.1 & 16.5 & 19.1 \\
\hline Top 1\% & 221 & 3.9 & 7.1 & 8.7 & 25.5 \\
\hline All Other Traders & 21,866 & 2.0 & 5.6 & 4.3 & 23.0 \\
\hline \multicolumn{6}{|l|}{ Trades Per Day } \\
\hline Top $0.01 \%$ & 2,179 & 91.8 & 133.5 & 235.0 & 675.0 \\
\hline Top $0.1 \%$ & 5,042 & 68.6 & 122.6 & 175.0 & 595.0 \\
\hline Top 1\% & 2,8062 & 28.3 & 71.1 & 63.0 & 316.0 \\
\hline All Other Traders & 697,877 & 7.0 & 19.1 & 14.0 & 63.0 \\
\hline \multicolumn{6}{|l|}{ Value Per Trade } \\
\hline Top $0.01 \%$ & 2,179 & $492,587.4$ & $66,136.0$ & $589,975.7$ & $673,218.9$ \\
\hline Top $0.1 \%$ & 5,042 & $472,215.6$ & $93,998.8$ & $583,273.5$ & $761,253.6$ \\
\hline Top $1 \%$ & 28,062 & $334,900.6$ & $129,218.0$ & $484,283.7$ & $731,847.0$ \\
\hline All Other Traders & 697,877 & $113,178.5$ & $101,092.6$ & $248,800.5$ & $499,007.0$ \\
\hline
\end{tabular}

Traders are ranked by their total profit. Rankings based on total or average return are similar. Summary statistics are within group, thus $P 90$ of the Top $1 \%$ is the $90^{\text {th }}$ percentile of the top $1 \%$ of traders.

\subsection{Traders are Often Financially Constrained}

A characteristic of gambling, including trading as gambling, is that it may be done with a very limited and fixed budget. Figure 8 describes how often traders are liquidity constrained. Specifically, it describes the proportion of all days in which their accounts are active that they fall into one of four categories. Panel 8a describes how often individuals are unable to trade at all - that is, they have no open positions and insufficient available funds in their margin account to open one. We can see that this is only rarely the case - perhaps because traders in this situation cease using their account. Panel $8 \mathrm{~b}$ shows that, similarly, very few traders ever have sufficient funds in their account to open a position and do not do so that day. Panels $8 \mathrm{c}$ and $8 \mathrm{~d}$ do the same for traders who already have one position open. It can be seen in Panels 8a and 8c that, ignoring the large numbers of traders 
who are never constrained, the distributions are otherwise approximately uniform, suggesting that those traders who are ever constrained are constrained on average around half of the time. One reason for this is that traders may not keep unnecessary funds in their account, moving money only when necessary for a trade. This implies that these traders either do not anticipate trading again or do not anticipate needing to transfer more funds for their future trades (i.e., they bet that the initial trades would be profitable). The other, non-contradictory, explanation is that traders, like visitors to casinos, have a fixed budget and 'play' with this. Note, that this also explains the $12 \%$ of individuals reported by the left-hand spike in Panel 8d who, given they have an open position, never have enough funds in order to be able to open another. That is, they only ever trade one contract. The spike in Panel 8c suggests that there are similarly around a quarter of traders who are never constrained given that they have an open position. This may comprise individuals who choose not to use their full margin, richer individuals who tend to trade many contracts, or simply those who know they will trade more in the future and leave funds in their account for this purpose. Taken together, we argue that the substantial proportion of traders who are invested to their limit much of the time, along with those who only ever open the smallest possible position, are consistent with gambling type behaviour. That is, trading for the enjoyment of trading rather than to maximise long-term investment returns.

\subsection{They tend to only trade one asset}

The final aspect of traders' behaviour that we consider is the fraction of their trading activity accounted for by Rebar futures. Traders have access to approximately 9,000 different assets. If they were simply trying to maximize their risk adjusted returns then we should expect them to trade a number of these to benefit from diversification. Even if Rebar are never in an optimal portfolio, conditional on trading Rebar we should expect traders to also trade other assets. We do not observe the full trading history for other assets, but we do observe changes in individuals' margin accounts due to this trading. We are thus able to reconstruct the aggregate extent and outcomes of their trades in all other assets. That is the extent to which observed changes in Margin Accounts are not due to (observed) Rebar trading or (observed) funds transfers they must be due to (unobserved) losses or gains in other assets. Figure 9 shows that $60 \%$ of traders trade exclusively Rebar. Further, nearly all individuals have a ratio of non-Rebar trade volumes to Rebar volumes of 1 or less, suggesting that they trade as much Rebar as anything else. We can, therefore, say that the majority of these traders only trade one or two assets. That there is a long-tail of individuals trading significantly more of 
other assets than Rebar might suggest that there is a fraction of relatively sophisticated investors. This hypothesis is compatible with the discussion of the most successful traders above.

In fact, inspection of Figure 10 suggests that almost all traders trade on a given day Rebar or another asset. Thus, whilst some traders' preferred asset may vary over the period very few frequently trade more than one on any one day. This is perhaps unsurprising given the lack of liquidity that characterises most traders seen in Figure 8.

\section{Conclusion}

Margin trading is popular with retail investors around the world. This is a puzzle since, as we have shown, margin trading has a negative expected return. We have demonstrated that whilst lowering mean returns, the collateral requirement imposed by margin calls also induces positive skew. As a result, investments offer limited losses and a small but positive chance of a large gain. Thus, margin trading offers the same hedonic returns associated with lottery tickets, lottery-type stocks, and gambling. We tested this hypothesis using a unique dataset on the full trading histories of Rebar futures traders on the Shanghai Futures Exchange (SHFE). We show that both expected and observed losses are substantial and that the optimal portfolio never contains Rebar futures. Analysing traders' behaviour, we found that whilst hard to rationalise without a hedonic motive, that trading behaviour can be easily understood as a form of entertainment.

There are implications of trading as entertainment, and of margin trading as entertainment, for policy. In particular, a system in which those trading for hedonic reasons are separated from those trading for investment may have much to recommend it. Such a separation may limit the amplifying properties of margin trading for the systemic consequences of large price shocks. In one sense the Rebar market we study is an example of this - its pricing is unrelated of that to the underlying asset and almost all trading is accounted for by traders whose behaviour can be best explained by hedonic or entertainment motivations. A large sell-off in this market would be less likely to engender the negative-spiral Brooks described happening in ' 62. 
Figure 8: A Lack of Liquidity often Prevents Traders Increasing their Position

(a) No Position, Can Not Open One

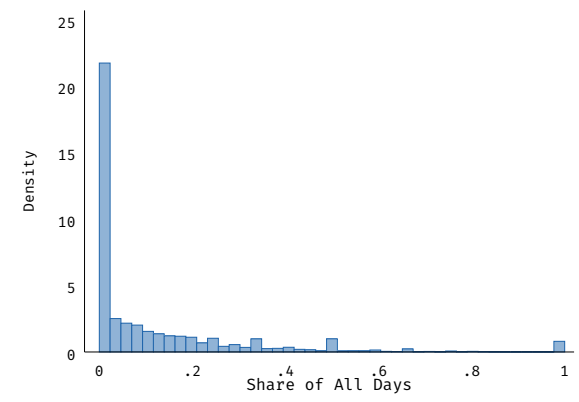

(c) Open Position, Can Not Open More

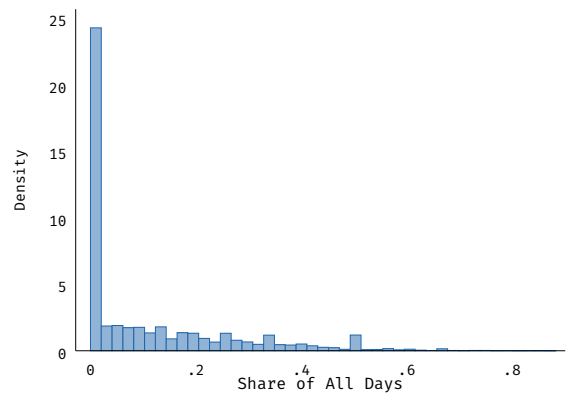

(b) No Position, Could Open One

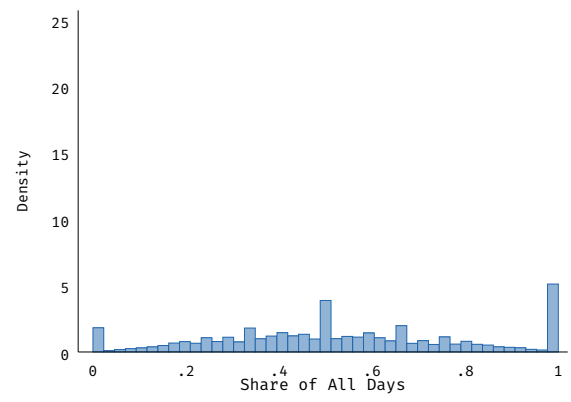

(d) Open Position, Could Open More

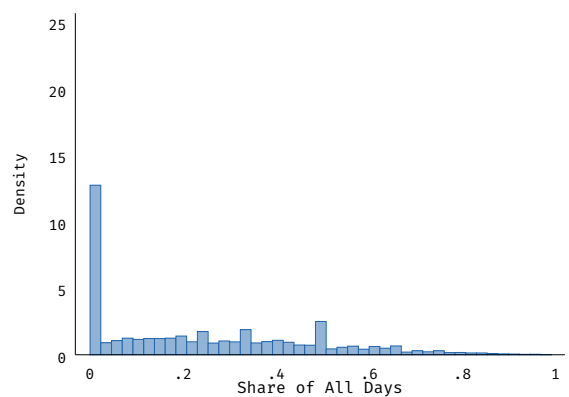

Figure 8a plots the proportion of all trader-days in which a trader has insufficient funds in their account to open a position and where they do not already have an open position. Figure $8 \mathrm{~b}$ similarly describes the proportion of trader-days in which a trader has no open position but could afford to open one if they preferred. Figure $8 \mathrm{c}$ describes the share of trader-days in which an individual with at least one open position can not afford to open another. Finally, Figure $8 \mathrm{~d}$ describes the fraction of trader-days with open positions and sufficient liquidity to open further positions. 
Figure 9: Ratio of Trade Values in Non-Rebar Assets to Rebar Futures

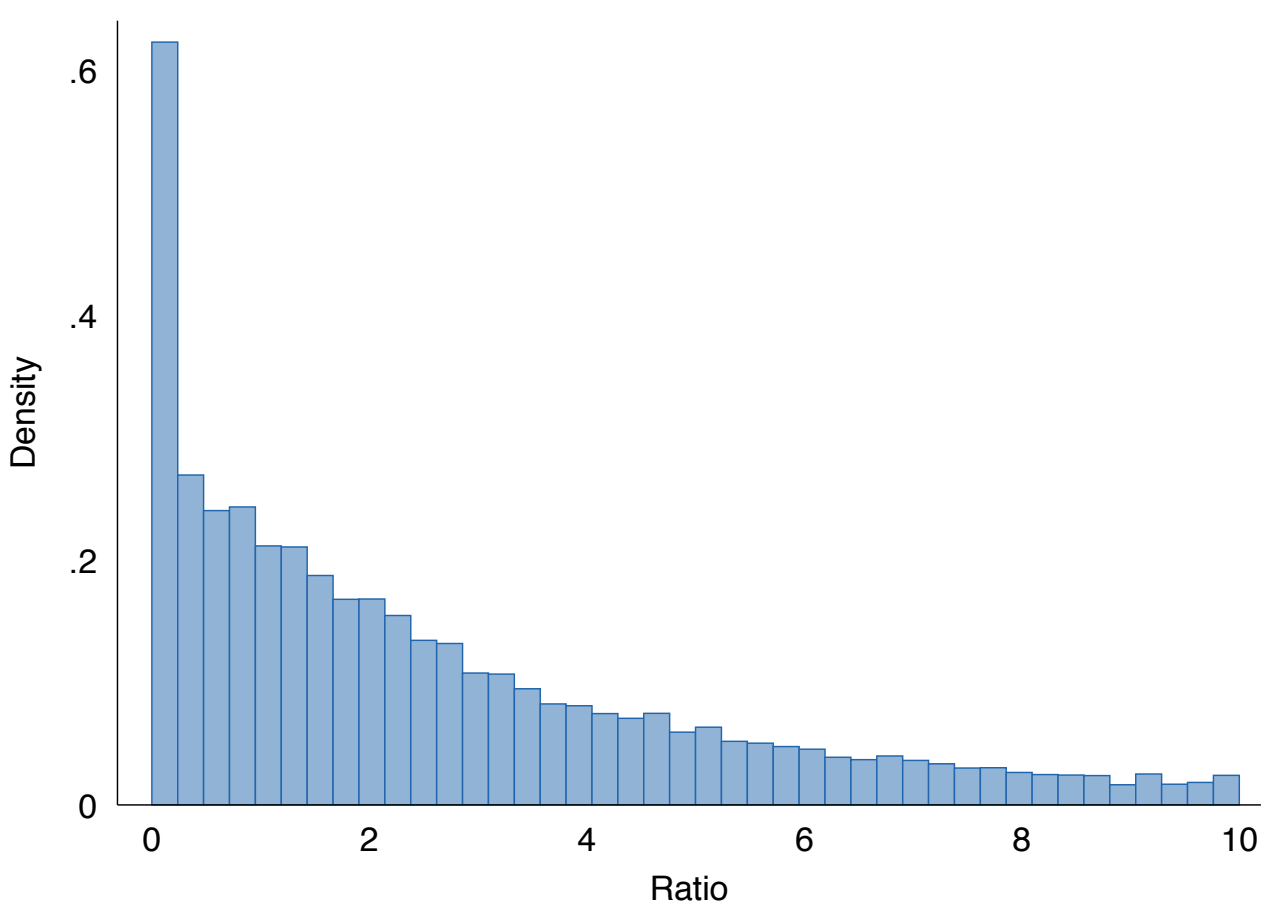

The variable Ratio describes the ratio of the total value of trades in non-rebar assets to the total value of rebar trades for each trader-day pair. The total for the non-rebar trades is the sum of all non-rebar assets available to clients of the brokerage.

Figure 10: Trading Volumes in Non-Rebar Assets to Rebar Futures

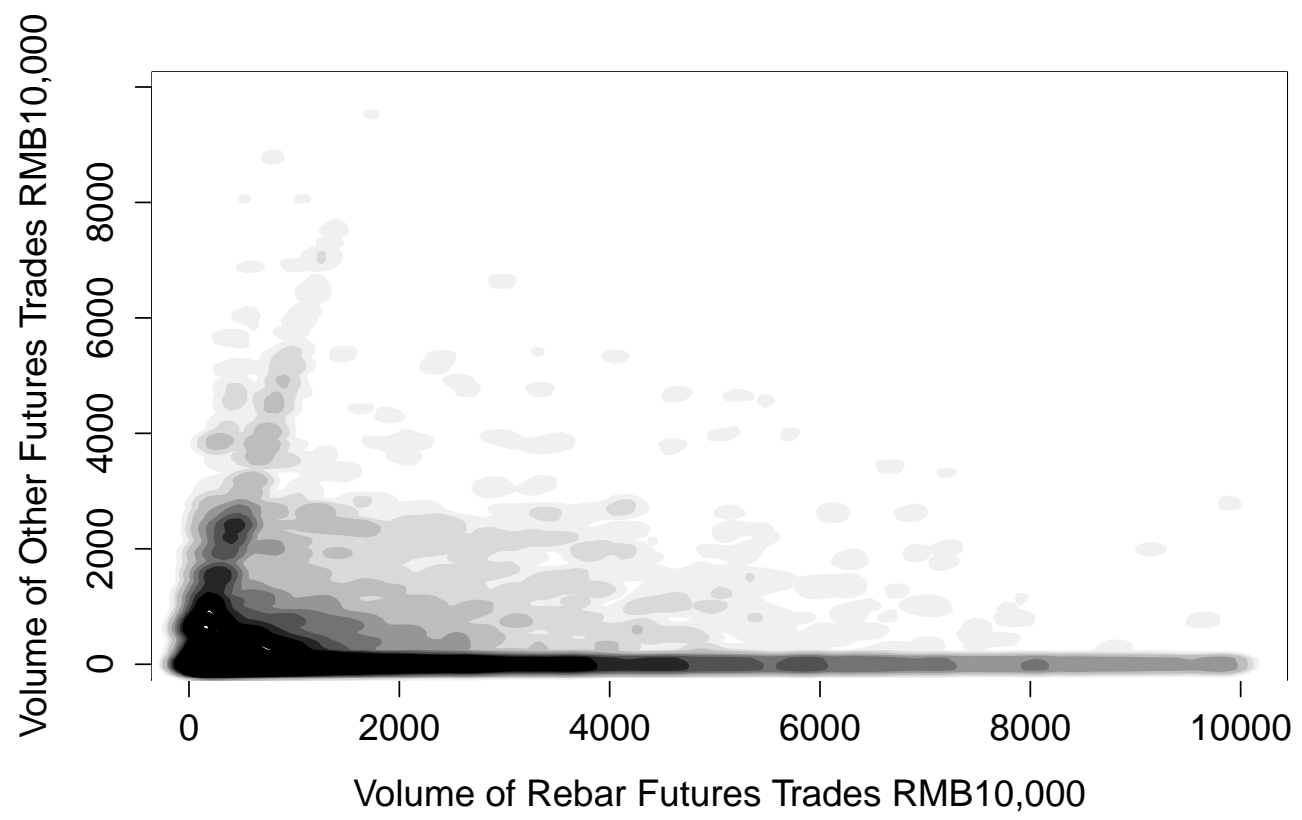

The plot is a heatmap describing the 2-dimensional kernel density surface estimated with an unconstrained bandwidth matrix chosen by smoothed cross-validation and a Gaussian kernel. The x-axis describes the volume of Rebar futures trades, while the y-axis is the total trading volume in all other assets. Units in both cases are in 10,000 RMB. 


\section{References}

Azevedo, E. M. and D. Gottlieb (2012): “Risk-neutral firms can extract unbounded profits from consumers with prospect theory preferences," Journal of Economic Theory, 147, 1291-1299.

Barber, B. M., Y. T. Lee, Y. J. Liu, and T. Odean (2009): “Just how much do individual investors lose by trading," Review of Financial Studies, 22, 609-632.

Barber, B. M. and T. Odean (2000): “Trading is Hazardous to Your Wealth: The Common Stock Investment Performance of Individual Investors," The Journal of Finance, 55, 773-806.

Barberis, N. (2012): “A Model of Casino Gambling,” Management Science, 58, 35-51.

Barberis, N. and M. Huang (2008): "Stocks as Lotteries: The Implications of Probability Weighting for Security Prices," American Economic Review, 98, 2066-2100.

Barberis, N. ANd W. Xiong (2012): “Realization utility,” Journal of Financial Economics, 104, 251-271.

Bhattacharya, N. and T. A. Garrett (2008): "Why people choose negative expected return assets an empirical examination of a utility theoretic explanation," Applied Economics, 40, 27-34.

Boyer, B. H. AND K. Vorkink (2014): “Stock options as lotteries," Journal of Finance, 69, 1485-1527.

Brooks, J. (2014): Business Adventures: Twelve Classic Tales from the World of Wall Street, Open Road Media.

Brunnermeier, M. K. and L. H. Pedersen (2009): “Market liquidity and funding liquidity," Review of Financial Studies, 22, 2201-2238.

Chowdhury, A. R. (1991): "Futures market efficiency: evidence from cointegration tests," Journal of Futures Markets, 11, 577-589.

Dorn, A. J., D. Dorn, And P. Sengmueller (2015): “Trading as Gambling,” Management Science, 61, 2376-2393.

Dorn, D. And P. Sengmueller (2009): “Trading as Entertainment?” Management Science, 55, 591603.

Friedman, M. And L. J. Savage (1948): “The Utility Analysis of Choices Involving Risk,” Journal of Political Economy, 56, 279. 
GaO, X. AND T.-C. Lin (2015): “Do Individual Investors Treat Trading as a Fun and Exciting Gambling Activity? Evidence from Repeated Natural Experiments," Review of Financial Studies, 28, 21282166.

Golec, J. And M. Tamarkin (1998): “Bettors Love Skewness, Not Risk, at the Horse Track,” Journal of Political Economy, 106, 205.

Heimer, R. Z. (2015): “Can Leverage Constraints Make ( Some ) Investors Better Off ?” Mimeo.

INGERSOLL, J. E. AND L. J. JIN (2012): "Realization Utility with Reference-Dependent Preferences," Review of Financial Studies, 26, 723-767.

Jayaraman, R., D. Ray, and F. de Véricourt (2016): “Anatomy of a Contract Change," American Economic Review, 106, 316-358.

Kahraman, C. B. and H. Tookes (2013): "Leverage constraints and liquidity: What can we learn from margin trading?" Mimeo.

Kindleberger, C. P. (2000): Manias, Panics and Crashes, John Wiley and Sons, New York.

Kumar, A. (2009): “Who gambles in the stock market?” Journal of Finance, 64, 1889-1933.

Kumar, A., J. K. Page, and O. G. Spalt (2011): "Religious beliefs, gambling attitudes, and financial market outcomes," Journal of Financial Economics, 102, 671-708.

Markowitz, H. (1952): “The Utility of Wealth,” Journal of Political Economy, 60, 151.

Parco, J. E., A. Rapoport, and W. Amaldoss (2005): “Two-stage contests with budget constraints: An experimental study," Journal of Mathematical Psychology, 49, 320-338.

Pender, J. (2015): "The truncated normal distribution: Applications to queues with impatient customers," Operations Research Letters, 43, 40-45.

Sheremeta, R. M. (2010): “Experimental comparison of multi-stage and one-stage contests," Games and Economic Behavior, 68, 731-747.

Shiller, R. J. (2000): Irrational Exuberance, Princeton University Press.

Shleifer, A. And R. W. Vishny (1997): “ The Limits of Arbitrage,” Journal of Finance, 52, 35-55.

WANG, Y. (2014): "Margin-Trading and Short-Selling with Asymmetric Information," Mimeo. 
Table 2: Correlations Between the Price of Rebar Futures and the Spot Price by Contract

\begin{tabular}{|c|c|c|c|c|c|c|}
\hline Code & Spot Opening & Spot Closing & Spot Settlement & $\Delta$ Opening & $\Delta$ Closing & $\Delta$ Settlement \\
\hline RB0909 & 0.93 & 0.94 & 0.93 & 0.54 & 0.39 & 0.48 \\
\hline RB0910 & 0.93 & 0.94 & 0.94 & 0.57 & 0.41 & 0.53 \\
\hline RB0911 & 0.92 & 0.93 & 0.92 & 0.49 & 0.35 & 0.48 \\
\hline RB0912 & 0.90 & 0.90 & 0.90 & 0.48 & 0.31 & 0.43 \\
\hline RB1001 & 0.89 & 0.90 & 0.89 & 0.41 & 0.28 & 0.42 \\
\hline RB1002 & 0.85 & 0.86 & 0.85 & 0.43 & 0.23 & 0.37 \\
\hline RB1003 & 0.82 & 0.82 & 0.82 & 0.42 & 0.27 & 0.39 \\
\hline RB1004 & 0.72 & 0.74 & 0.74 & 0.38 & 0.25 & 0.37 \\
\hline RB1005 & 0.56 & 0.55 & 0.55 & 0.40 & 0.24 & 0.39 \\
\hline RB1006 & 0.36 & 0.34 & 0.34 & 0.42 & 0.24 & 0.38 \\
\hline RB1007 & 0.29 & 0.27 & 0.28 & 0.37 & 0.22 & 0.36 \\
\hline RB1008 & 0.14 & 0.13 & 0.13 & 0.19 & 0.13 & 0.22 \\
\hline RB1009 & 0.17 & 0.14 & 0.15 & 0.41 & 0.25 & 0.38 \\
\hline RB1010 & 0.09 & 0.07 & 0.08 & 0.40 & 0.25 & 0.38 \\
\hline RB1011 & -0.00 & -0.02 & -0.02 & 0.32 & 0.27 & 0.37 \\
\hline RB1012 & 0.22 & 0.22 & 0.22 & 0.38 & 0.30 & 0.45 \\
\hline RB1101 & 0.49 & 0.49 & 0.49 & 0.44 & 0.23 & 0.39 \\
\hline RB1102 & 0.70 & 0.69 & 0.69 & 0.41 & 0.28 & 0.41 \\
\hline RB1103 & 0.86 & 0.86 & 0.85 & 0.41 & 0.28 & 0.39 \\
\hline RB1104 & 0.94 & 0.94 & 0.94 & 0.42 & 0.27 & 0.37 \\
\hline RB1105 & 0.96 & 0.95 & 0.96 & 0.38 & 0.22 & 0.33 \\
\hline RB1106 & 0.96 & 0.96 & 0.96 & 0.23 & 0.22 & 0.32 \\
\hline RB1107 & 0.90 & 0.89 & 0.90 & 0.30 & 0.15 & 0.29 \\
\hline RB1108 & 0.89 & 0.89 & 0.90 & 0.31 & 0.26 & 0.33 \\
\hline RB1109 & 0.79 & 0.79 & 0.77 & 0.31 & 0.16 & 0.23 \\
\hline RB1110 & 0.50 & 0.48 & 0.49 & 0.30 & 0.10 & 0.26 \\
\hline RB1111 & 0.70 & 0.70 & 0.67 & 0.19 & 0.29 & 0.34 \\
\hline RB1112 & 0.80 & 0.80 & 0.80 & 0.14 & 0.22 & 0.22 \\
\hline RB1201 & 0.85 & 0.84 & 0.85 & 0.33 & 0.23 & 0.30 \\
\hline RB1202 & 0.91 & 0.91 & 0.91 & 0.19 & 0.25 & 0.26 \\
\hline RB1203 & 0.93 & 0.93 & 0.93 & 0.24 & 0.13 & 0.22 \\
\hline RB1204 & 0.95 & 0.95 & 0.95 & 0.24 & 0.18 & 0.24 \\
\hline RB1205 & 0.95 & 0.95 & 0.95 & 0.21 & 0.23 & 0.29 \\
\hline RB1206 & 0.95 & 0.95 & 0.95 & 0.26 & 0.25 & 0.28 \\
\hline RB1207 & 0.93 & 0.92 & 0.93 & 0.25 & 0.26 & 0.26 \\
\hline RB1208 & 0.93 & 0.93 & 0.93 & 0.26 & 0.18 & 0.24 \\
\hline RB1209 & 0.94 & 0.94 & 0.94 & 0.27 & 0.16 & 0.28 \\
\hline RB1210 & 0.94 & 0.93 & 0.93 & 0.27 & 0.22 & 0.30 \\
\hline RB1211 & 0.94 & 0.95 & 0.95 & 0.23 & 0.26 & 0.30 \\
\hline RB1212 & 0.97 & 0.97 & 0.98 & 0.34 & 0.23 & 0.30 \\
\hline RB1301 & 0.97 & 0.96 & 0.97 & 0.36 & 0.13 & 0.31 \\
\hline RB1302 & 0.96 & 0.95 & 0.96 & 0.27 & 0.15 & 0.28 \\
\hline RB1303 & 0.94 & 0.94 & 0.94 & 0.24 & 0.13 & 0.26 \\
\hline RB1304 & 0.90 & 0.89 & 0.89 & 0.32 & 0.21 & 0.26 \\
\hline RB1305 & 0.82 & 0.81 & 0.81 & 0.33 & 0.10 & 0.26 \\
\hline RB1306 & 0.81 & 0.80 & 0.81 & 0.27 & 0.15 & 0.27 \\
\hline RB1307 & 0.85 & 0.85 & 0.85 & 0.29 & 0.16 & 0.24 \\
\hline RB1308 & 0.83 & 0.83 & 0.84 & 0.24 & 0.08 & 0.20 \\
\hline RB1309 & 0.78 & 0.76 & 0.77 & 0.23 & 0.11 & 0.24 \\
\hline RB1310 & 0.80 & 0.79 & 0.79 & 0.26 & 0.07 & 0.21 \\
\hline
\end{tabular}

The column Spot Opening is the correlations between the Spot price of Rebar and the Opening price of Rebar Futures. Spot Closing is the correlation between the Spot price of Rebar and the Closing Price of Rebar Futures, and Settlement similarly the correlation with the reported settlement price. The columns $\Delta$ Spot Opening, $\Delta$ Spot Closing, and $\Delta$ Settlement report the correlations between the first differences of the prices. Bold-font contract-code denotes that a contract was one that was heavily traded as discussed in Section 4. 
Table 3: Cointegration Coefficients Between Rebar Future and Spot Prices

\begin{tabular}{cccc|cccc}
\hline Code & $Z_{\text {settlement }}$ & $Z_{\text {close }}$ & $Z_{\text {open }}$ & Code & $Z_{\text {settlement }}$ & $Z_{\text {close }}$ & $Z_{\text {open }}$ \\
\hline RB0909 & -2.06 & -2.31 & -2.02 & RB1110 & -2.18 & -2.28 & -2.18 \\
RB0910 & -2.14 & -2.46 & -2.21 & RB1111 & -1.77 & -1.95 & -2.75 \\
RB0911 & -2.06 & -2.43 & -2.41 & RB1112 & -1.27 & -1.23 & -2.13 \\
RB0912 & -2.37 & -2.66 & -2.76 & RB1201 & -1.52 & -1.73 & -1.70 \\
RB1001 & -2.55 & -2.99 & -3.15 & RB1202 & -2.07 & -2.08 & -2.87 \\
RB1002 & -2.21 & -2.56 & -2.84 & RB1203 & -2.85 & -2.97 & -3.17 \\
RB1003 & -1.66 & -2.08 & -2.05 & RB1204 & -2.99 & -3.11 & $-3.46^{*}$ \\
RB1004 & -0.85 & -1.20 & -1.69 & RB1205 & -2.46 & -2.88 & $-3.43^{*}$ \\
RB1005 & -0.03 & -0.40 & -0.66 & RB1206 & -2.75 & -2.87 & $-3.40^{*}$ \\
RB1006 & -0.77 & -0.88 & -0.85 & RB1207 & -2.66 & -2.59 & -2.69 \\
RB1007 & -0.81 & -0.88 & -0.87 & RB1208 & -2.70 & -2.74 & -2.92 \\
RB1008 & -0.60 & -0.61 & -0.61 & RB1209 & -2.32 & -2.72 & -2.92 \\
RB1009 & -0.57 & -0.62 & -0.53 & RB1210 & -2.94 & -3.34 & -3.32 \\
RB1010 & -1.59 & -1.60 & -1.57 & RB1211 & $-3.37^{*}$ & $-3.46^{*}$ & $-3.87^{*}$ \\
RB1011 & -0.77 & -0.76 & -0.78 & RB1212 & $-3.66^{*}$ & $-4.01^{* *}$ & $-3.94^{*}$ \\
RB1012 & -1.23 & -1.23 & -1.23 & RB1301 & -2.75 & -3.35 & -3.06 \\
RB1101 & -1.66 & -1.71 & -1.57 & RB1302 & -2.69 & -3.15 & -3.28 \\
RB1102 & -2.51 & -2.48 & -2.50 & RB1303 & -2.76 & -2.98 & $-3.44^{*}$ \\
RB1103 & -3.18 & $-3.43^{*}$ & -2.96 & RB1304 & -2.57 & -2.76 & -2.98 \\
RB1104 & -3.15 & $-3.64^{*}$ & $-3.60^{*}$ & RB1305 & -2.31 & -2.61 & -2.49 \\
RB1105 & $-4.70^{* *}$ & $-5.78^{* *}$ & $-5.17^{* *}$ & RB1306 & -2.61 & -2.77 & -2.93 \\
RB1106 & $-4.29^{* *}$ & $-4.86^{* *}$ & $-7.02^{* *}$ & RB1307 & -2.87 & -3.01 & -2.94 \\
RB1107 & -1.55 & -2.77 & -2.67 & RB1308 & -2.27 & -2.50 & -2.63 \\
RB1108 & -3.20 & $-3.66^{*}$ & $-3.94^{*}$ & RB1309 & -1.68 & -1.95 & -2.12 \\
RB1109 & -2.11 & -2.37 & -2.91 & RB1310 & -2.42 & -2.60 & -2.59 \\
\hline$Z$ Zertent
\end{tabular}

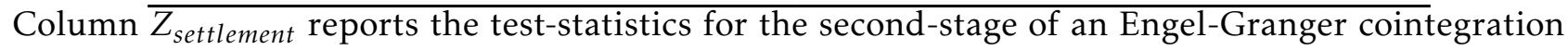
test between the Settlement Price and the Spot-Market. $Z_{\text {close }}$ and $Z_{\text {open }}$ report the same for cointegration tests between the Closing price and the Opening price respectively. ${ }^{*}$ denotes significance at the $5 \%$ level, and ${ }^{* *}$ at the $1 \%$ level. 


\section{A Additional Figures}

Figure A1: Returns, per position, Excluding Transaction Costs
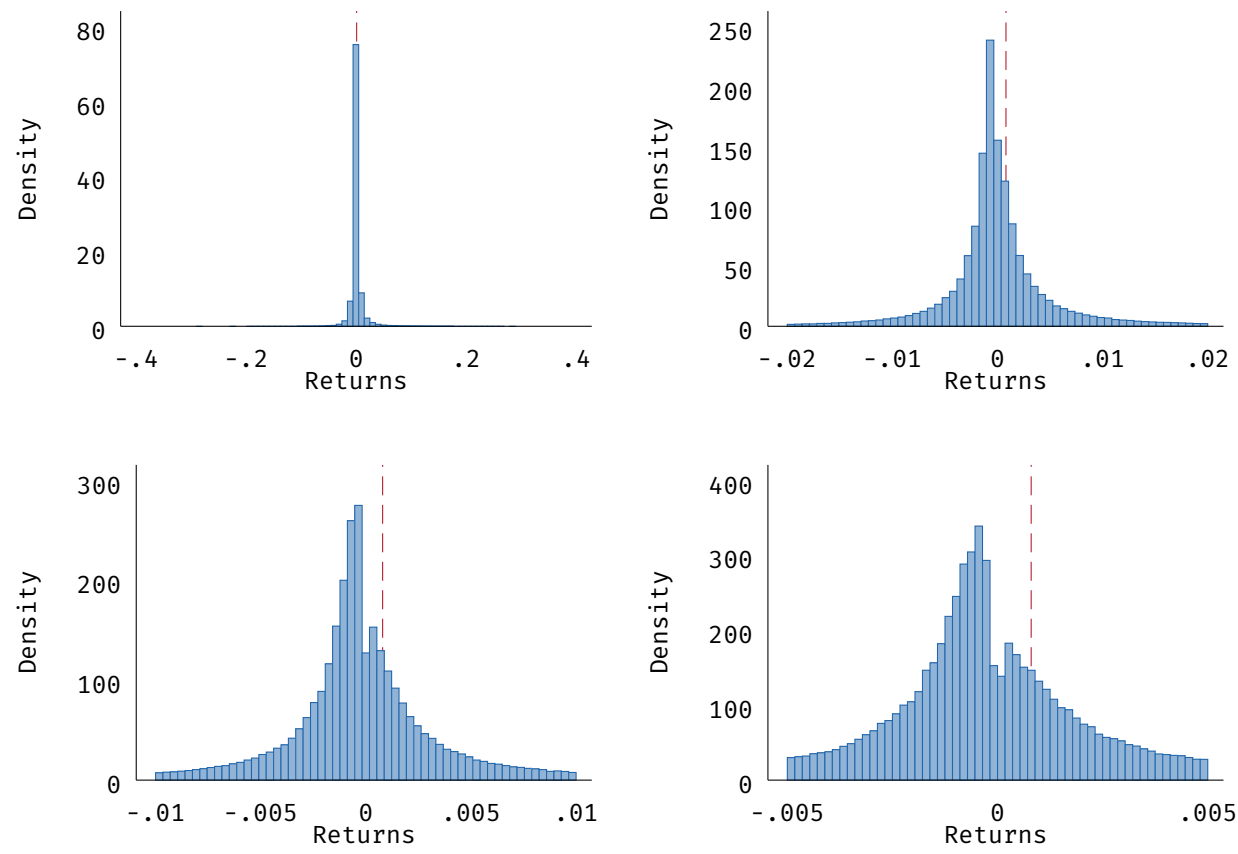

Returns are the absolute return for each position opened weighted by size. For clarity, the top-left distribution is truncated at \pm 0.1 ; the top right distribution at \pm 0.02 ; the bottom left distribution at \pm 0.01 ; and the bottom right distribution at \pm 0.005 . 
Figure A2: Comparison of Returns Distributions of Constrained and Unconstrained Traders
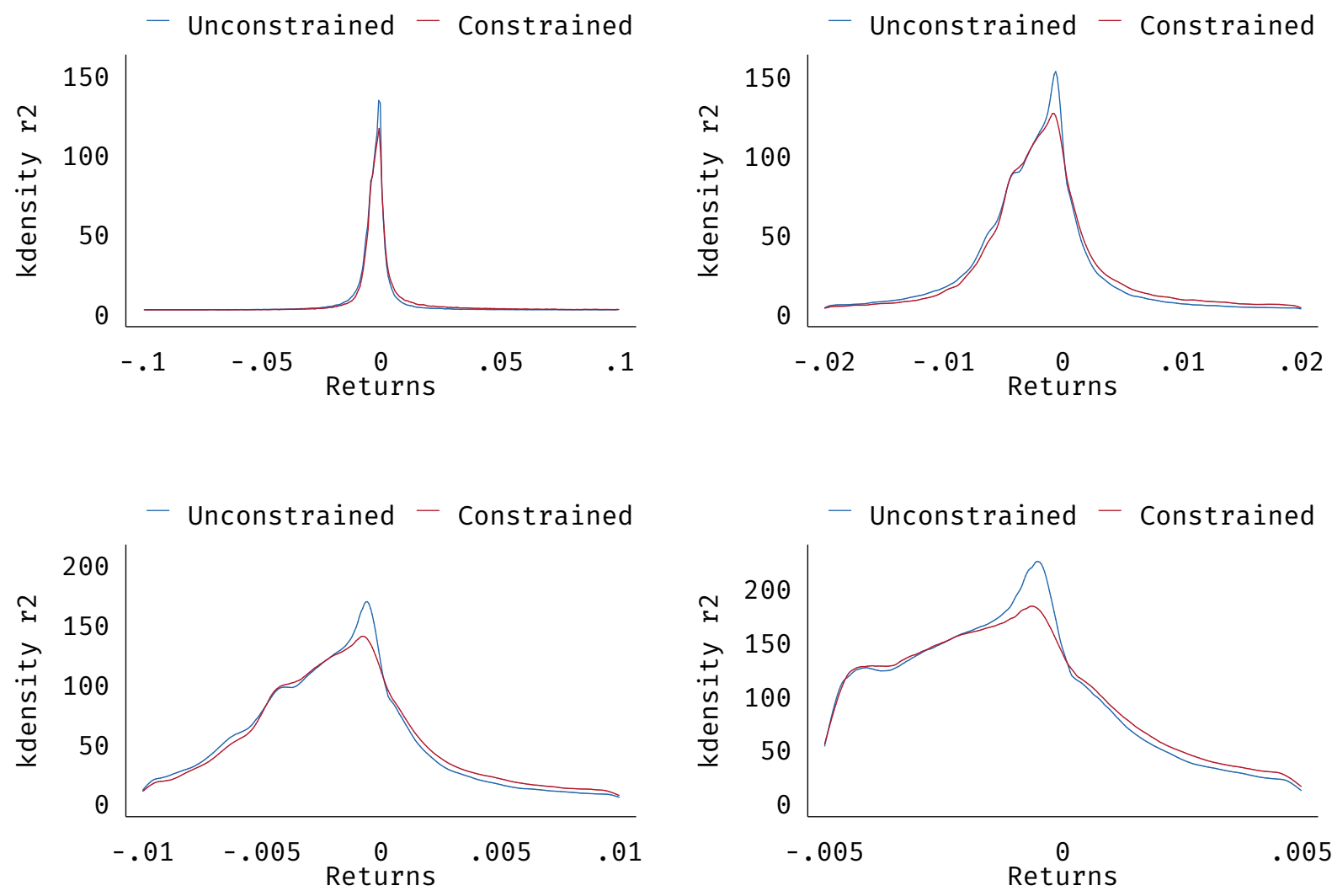

The figures describe the difference in the distributions of absolute returns obtained by constrained - those traders identified as having no additional investable funds - and unconstrained traders - those able to meet a margin call with additional funds. The top-left distribution is truncated for clarity, at \pm 0.1 , the top right distribution at \pm 0.02 the bottom left distribution at \pm 0.01 , and the bottom right distribution at \pm 0.005 . 
Figure A3: Returns, per position, Excluding Transaction Costs, Non-Constrained Traders
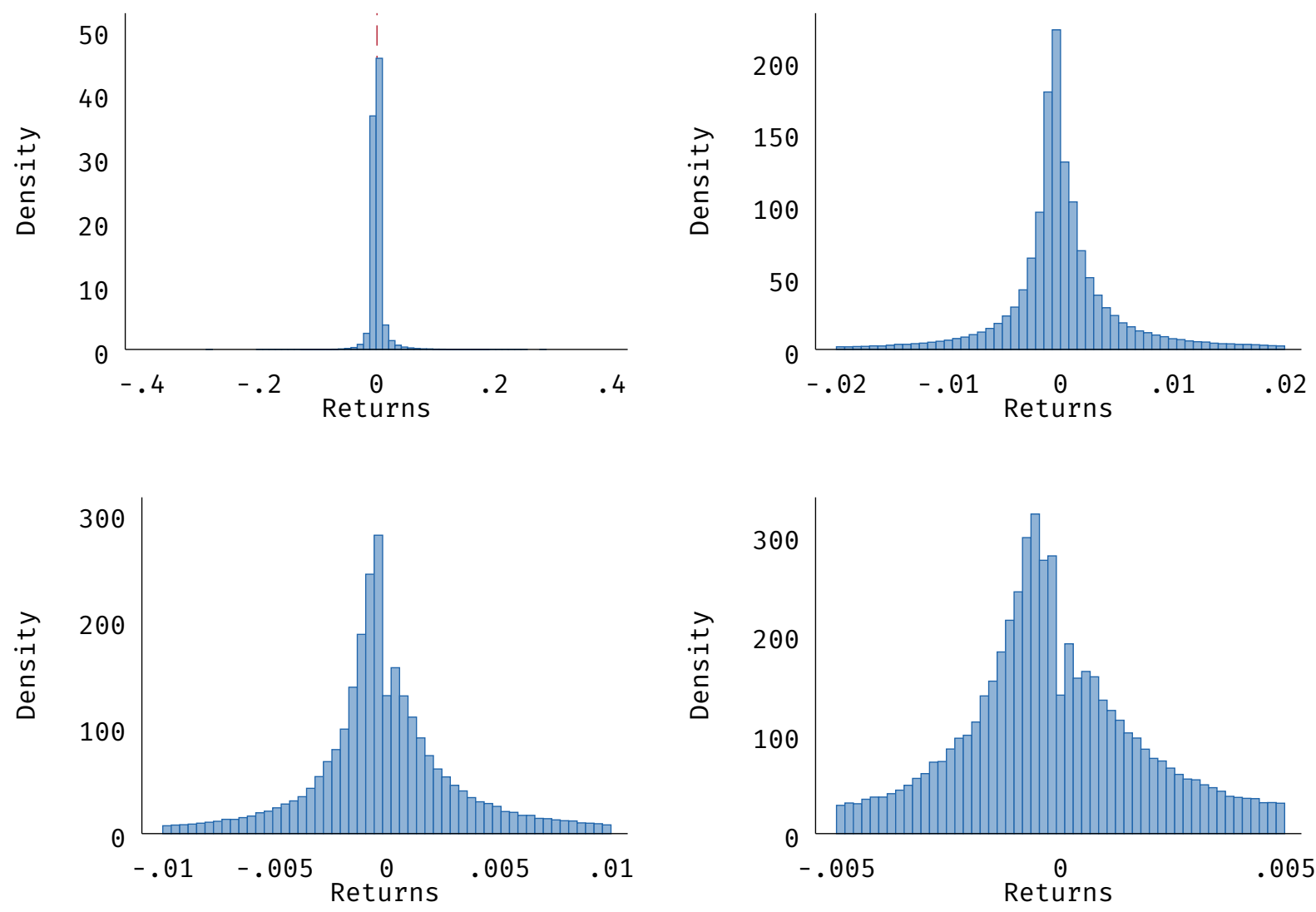

The figures describe the absolute returns obtained by unconstrained traders - those able to meet a margin call with additional funds - before trading costs are taken into account. The red dashed vertical line is the mean daily return. For clarity, the top-right distribution is truncated at \pm 0.02 ; the bottom left distribution at \pm 0.01 ; and the bottom right distribution at \pm 0.005 . 
Figure A4: Returns Including Transaction Costs
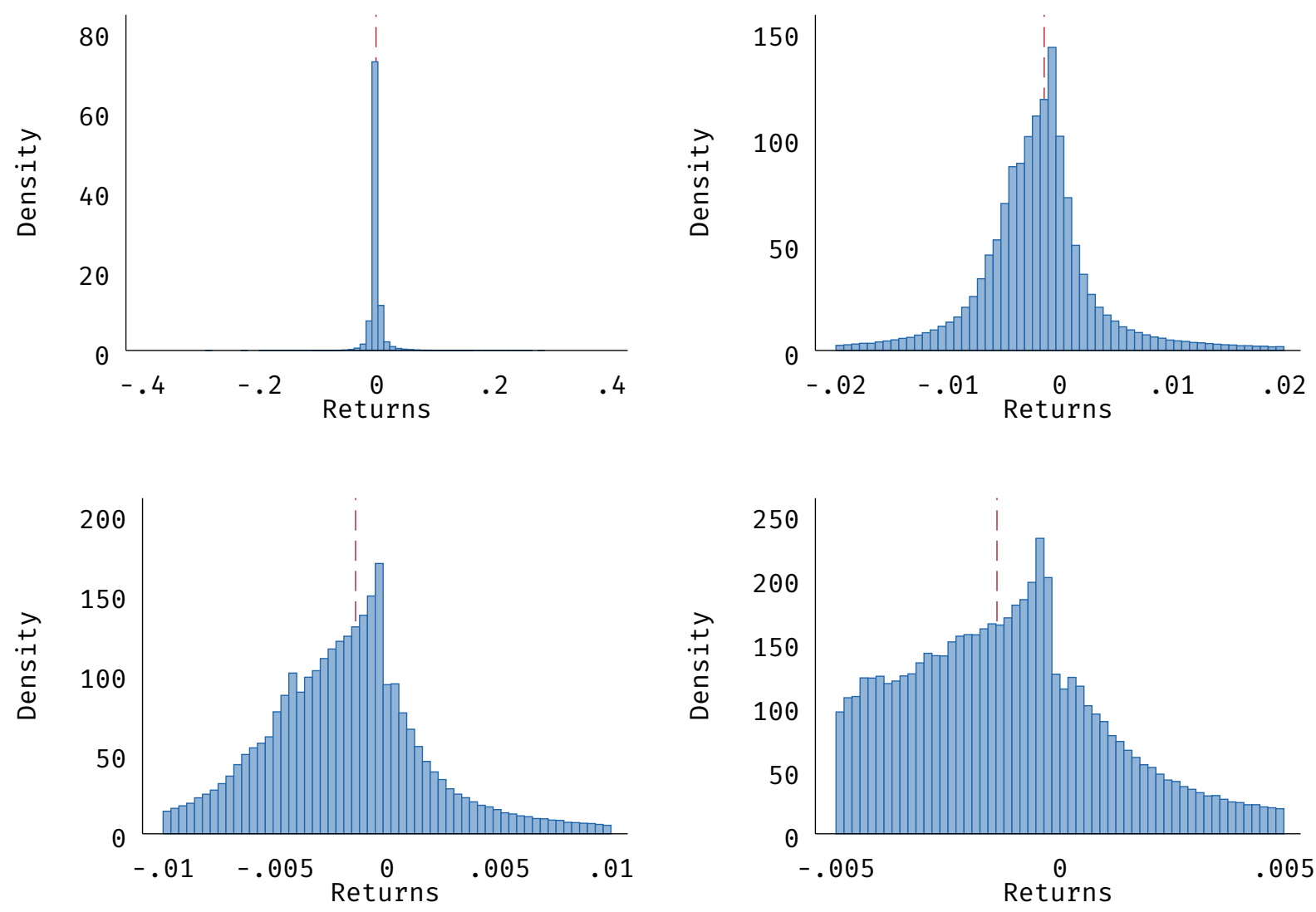

The figures describe the absolute returns obtained by constrained - those traders identified as having no additional investable funds - before trading costs are taken into account. The red dashed vertical line is the mean daily return. For clarity, the top-right distribution is truncated at \pm 0.02 ; the bottom left distribution at \pm 0.01 ; and the bottom right distribution at \pm 0.005 . 
Figure A5: Average Returns Measure

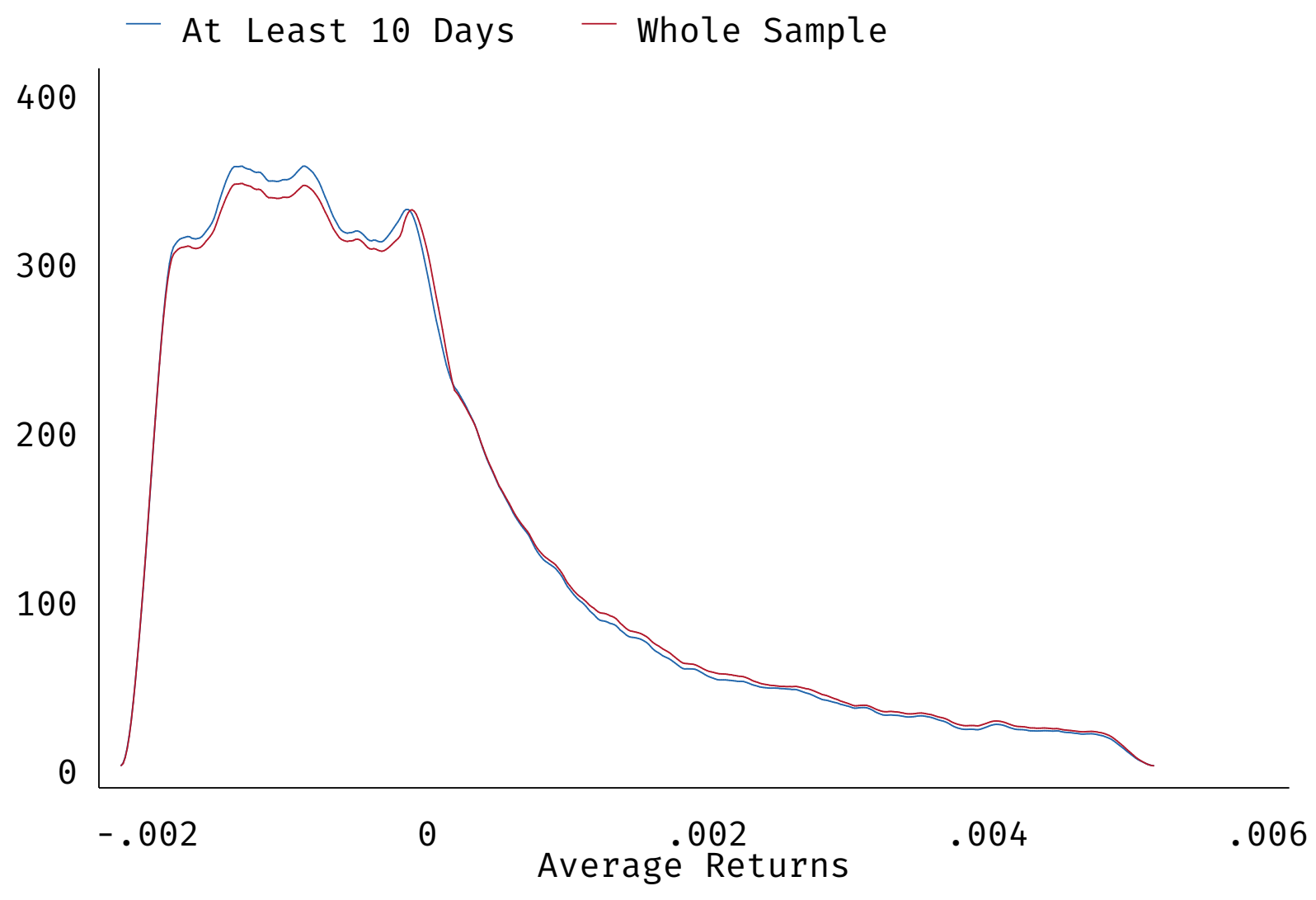

The figure shows that the the distribution of average returns changes little depending whether it is computed using the whole-sample (the red line) and only using those sub-periods of at least ten days in length (the blue line). 
Figure A6: Number of Days in Trading Sub-Periods

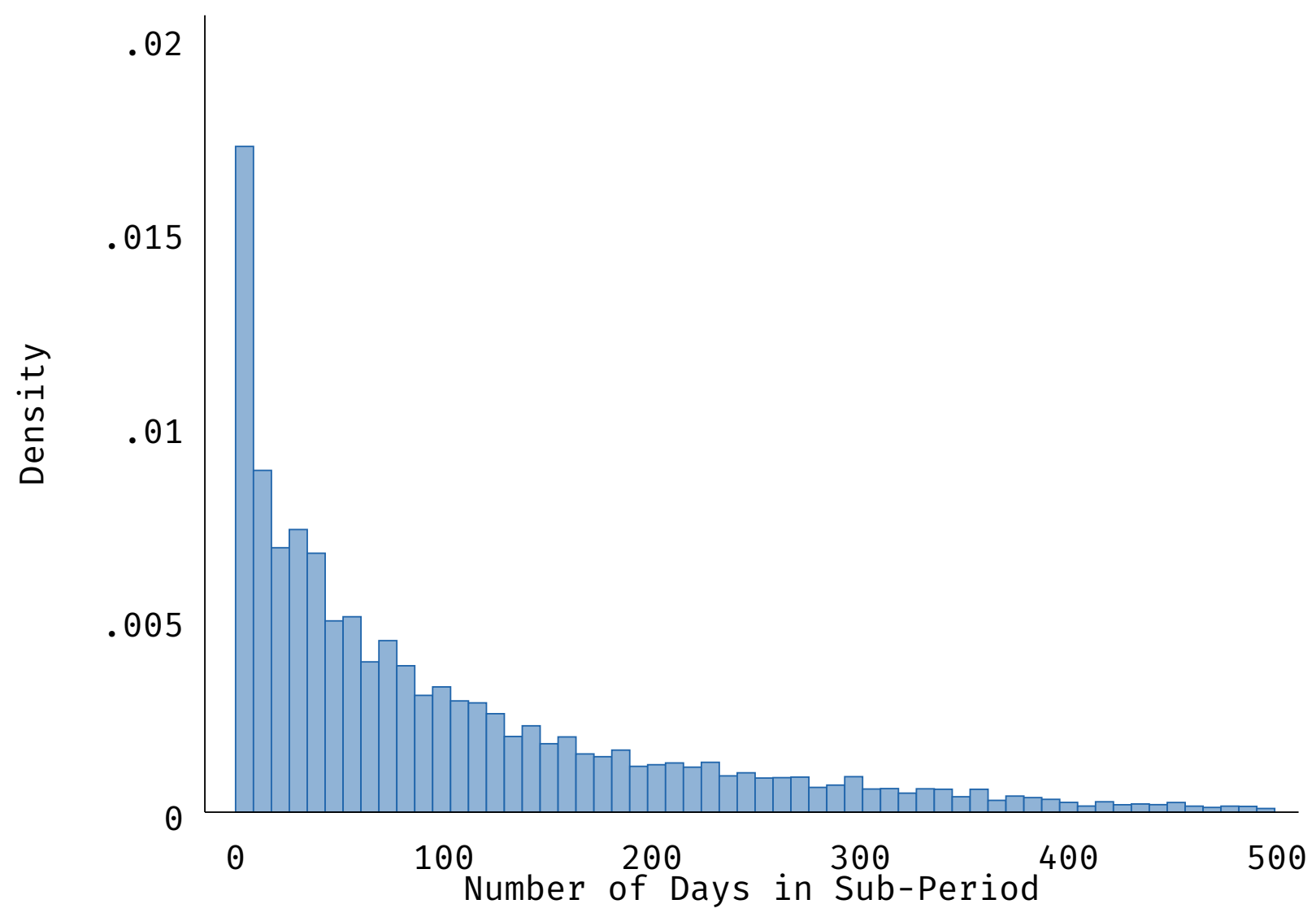

This figure describes the number of days in each of the the separate trading-episodes identified by the clustering algorithm. The Distribution is truncated at 500 days for clarity. 
Figure A7: One Rebar Contract Accounts For Almost All Trading Volume at Any Given Time

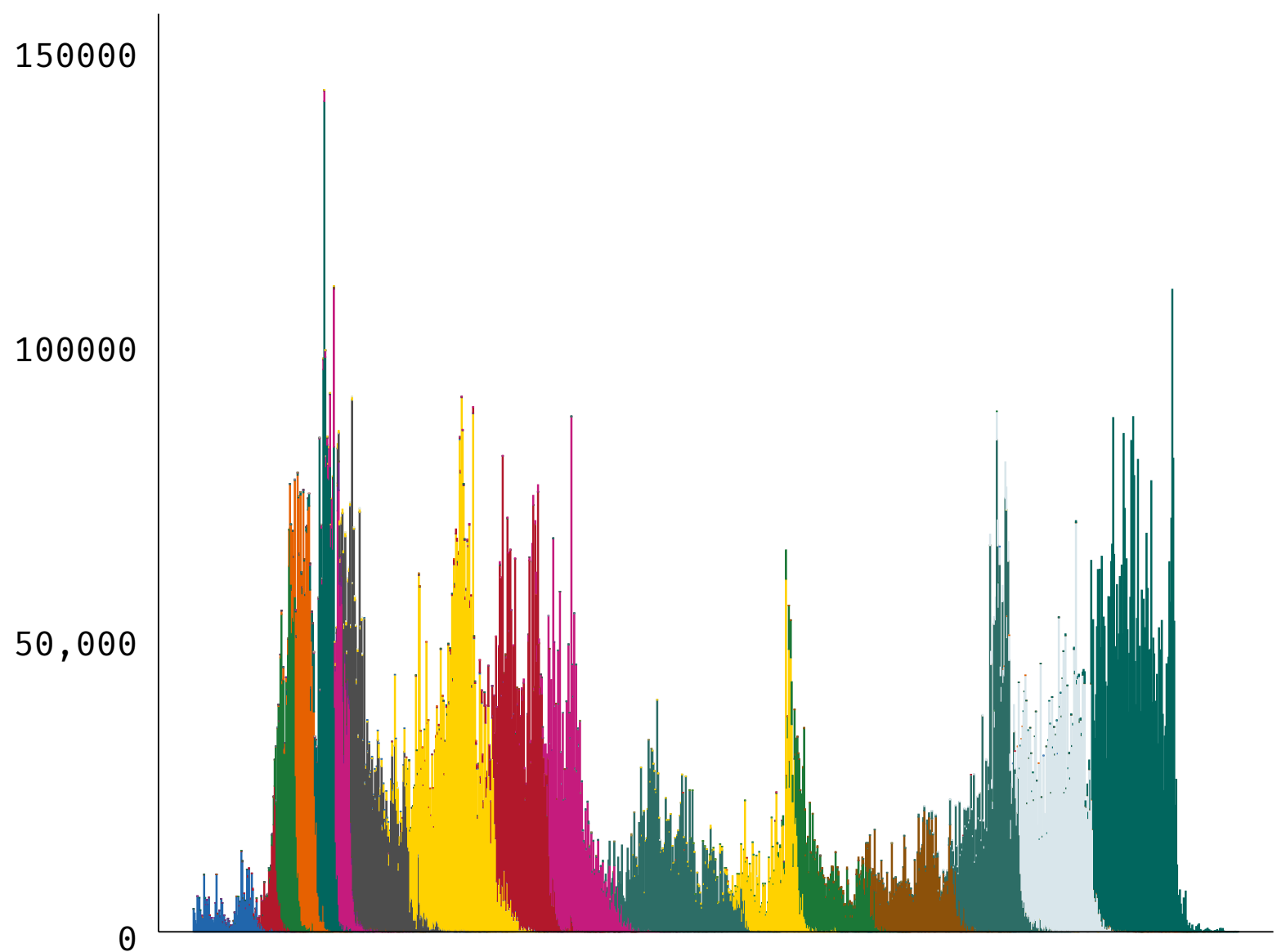

The graph is a stacked bar chart describing the evolution of total trading volume over time and its composition. At any one time normally only one colour is visible reflecting that almost all trading activity is normally focussed on one contract at any one time. The number of contracts visible is relatively few, reflecting that only three contracts (more at the beginning of our period) are actively traded a year. 
Figure A8: 2009 Rebar Contracts

Price of RB0909-RB0912 and 3 Spot Market

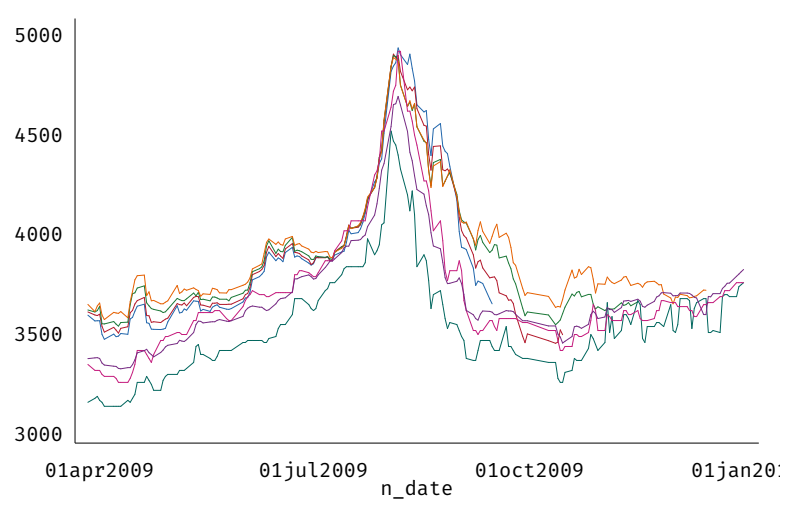

(a) Price

Market Position of RB0909-RB0912

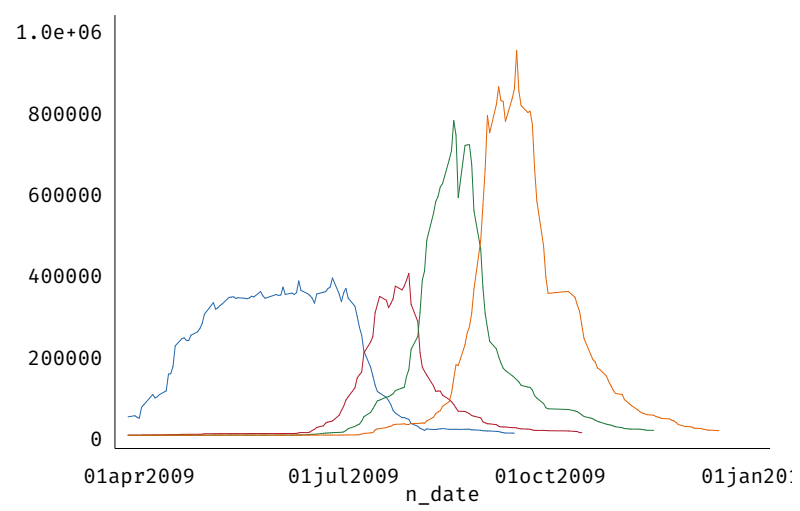

(c) Market Position
Daily Trading Volumes of RB0909-RB0912

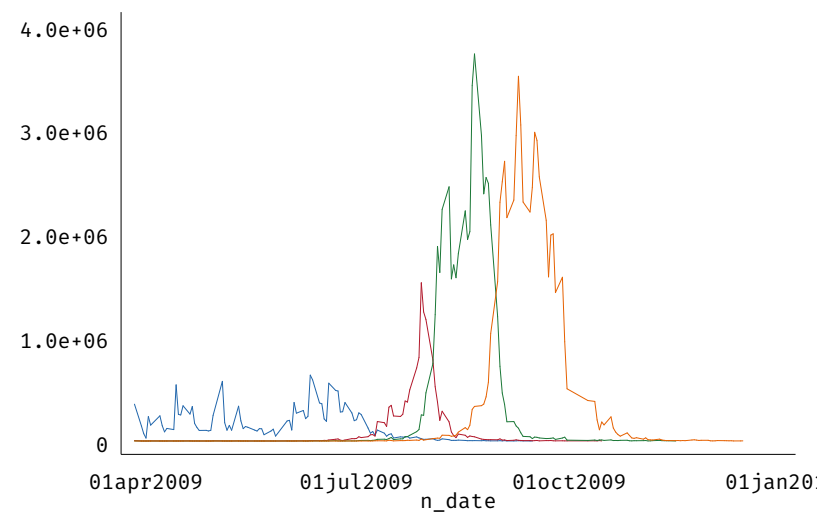

(b) Volume

Volatility of RB0909-RB0912 and 3 Spot Marl

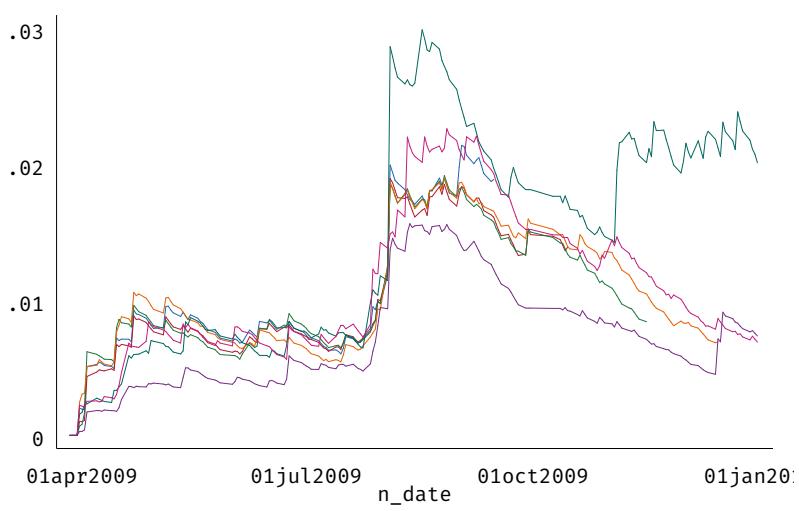

(d) Volatility

Figures describe Price (in RMB), Volume (Contracts), Net Market Position (Open Interest), Volatility (Exponential Moving Average of the Variance of the Log Return $\lambda=0.94$ ) of contracts RB0901-RB0912; that is, contracts for delivery in 2009. In Figure A8a the thick blue line is the volume weighted average of the price of all 12 contracts. Figure A8b reflects that only three contracts have any substantial volume of trades as does A8c. The thick blue line in panel A8d shows the average price volatility of all contracts. 
Figure A9: 2010 Rebar Contracts

Price of RB1001-RB1012 and 3 Spot Market

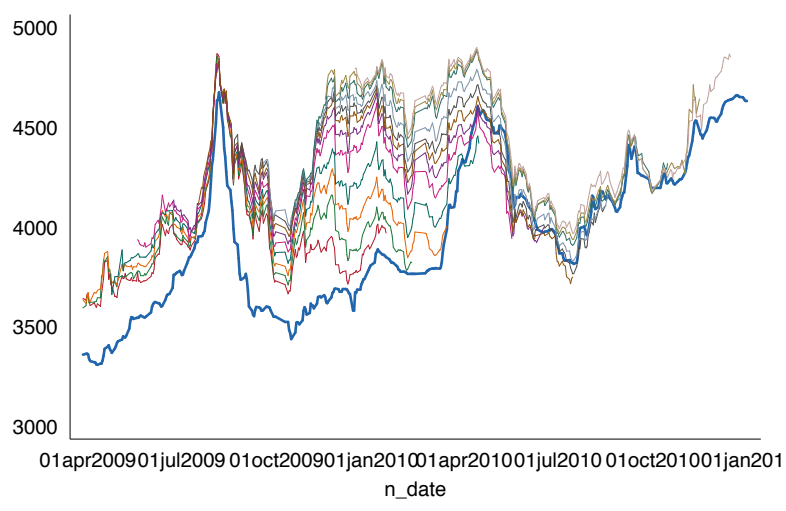

(a) Price

Market Position of RB1001-RB1012

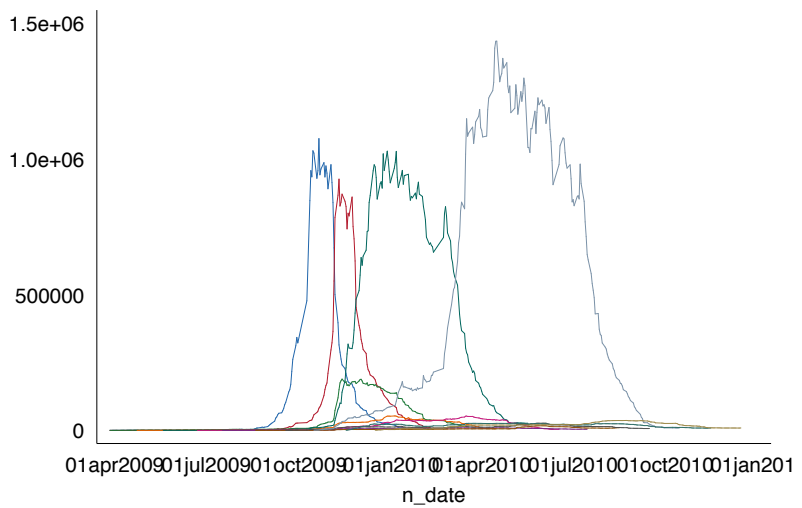

(c) Market Position
Daily Trading Volumes of RB1001-RB1012

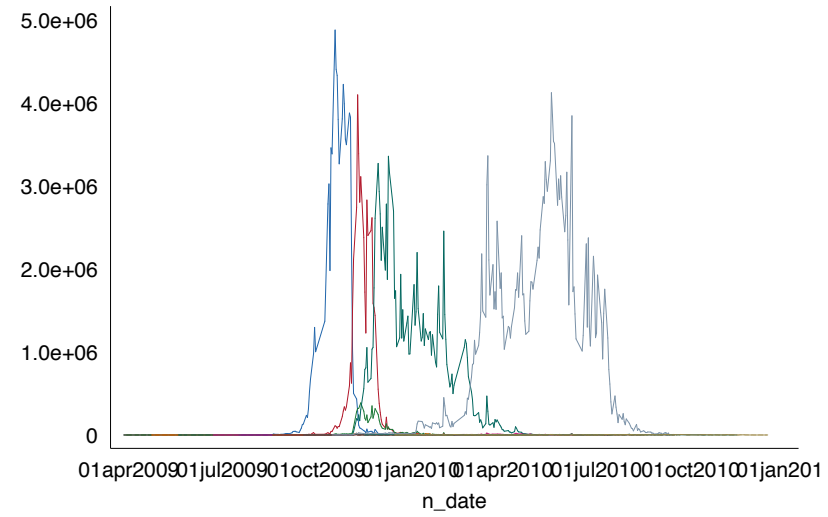

(b) Volume

Volatility of RB1001-RB1012 and 3 Spot Market

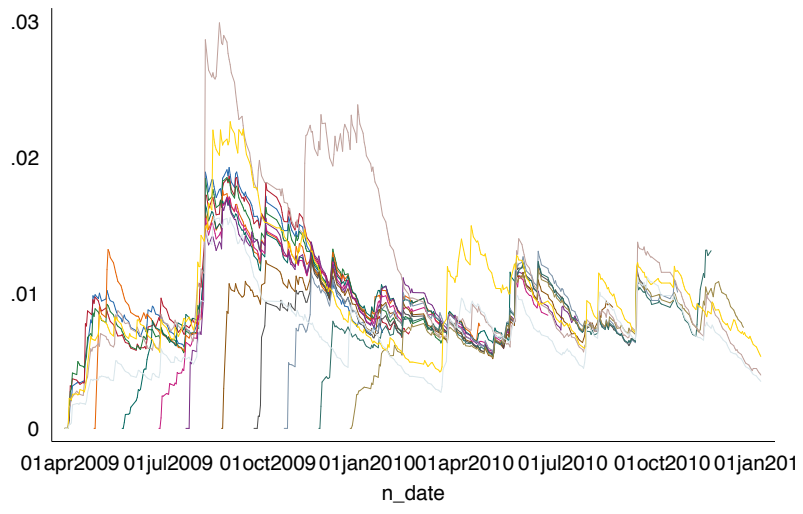

(d) Volatility

Figures describe Price (in RMB), Volume (Contracts), Net Market Position (Open Interest), Volatility (Exponential Moving Average of the Variance of the Log Return $\lambda=0.94$ ) of contracts RB1001-RB1012; that is, contracts for delivery in 2010. In Figure A9a the thick blue line is the volume weighted average of the price of all 12 contracts. Figure A9b reflects that only three contracts have any substantial volume of trades as does A9c. The thick blue line in panel A9d shows the average price volatility of all contracts. 
Figure A10: 2011 Rebar Contracts

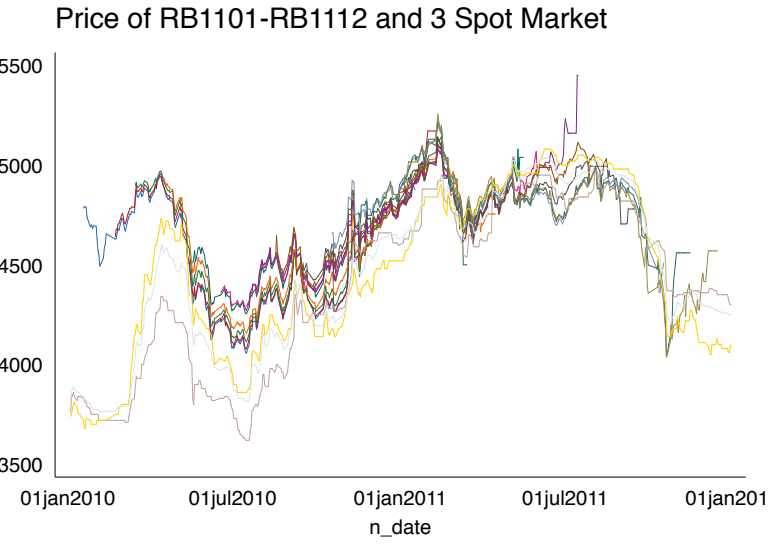

(a) Price

Market Position of RB1101-RB1112

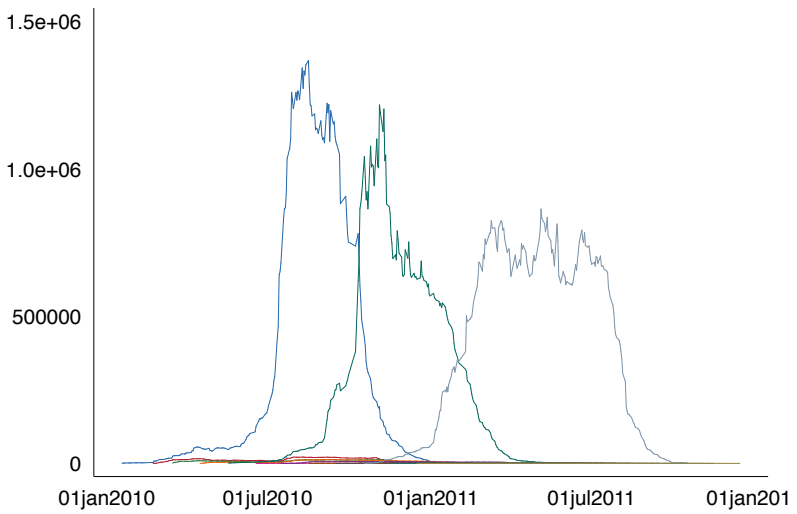

(c) Market Position
Daily Trading Volumes of RB1101-RB1112

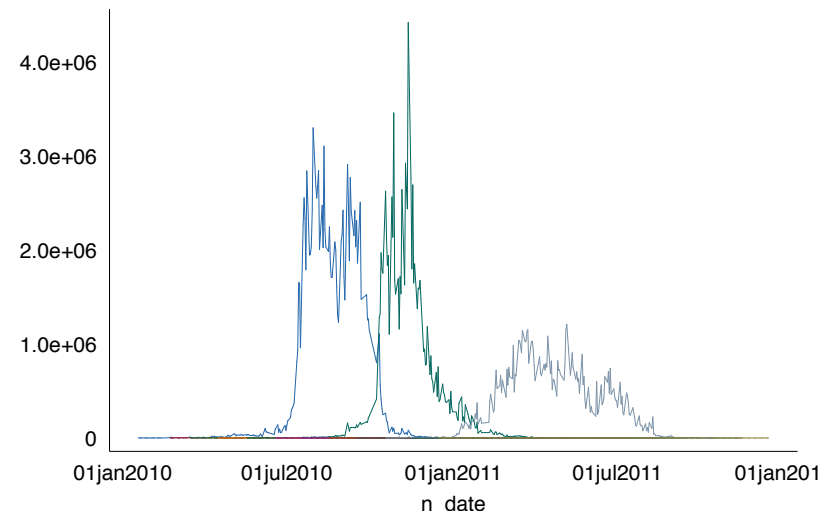

(b) Volume

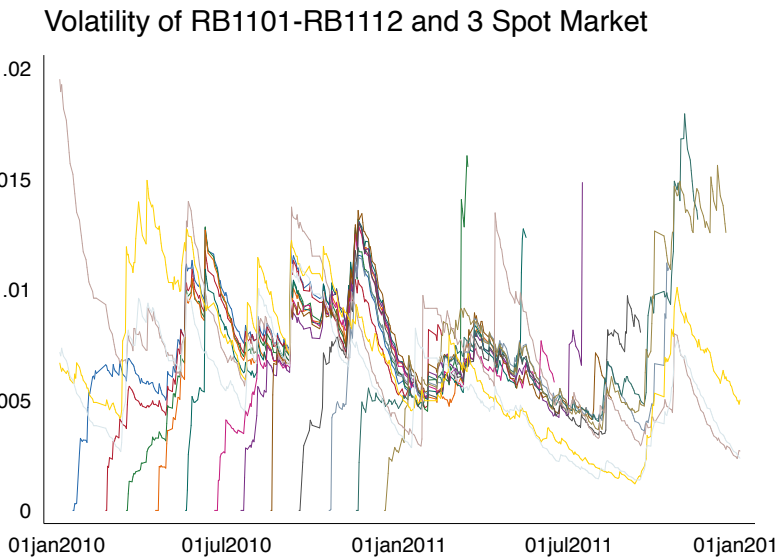

(d) Volatility

Figures describe Price (in RMB), Volume (Contracts), Net Market Position (Open Interest), Volatility (Exponential Moving Average of the Variance of the Log Return $\lambda=0.94$ ) of contracts RB1101-RB1112; that is, contracts for delivery in 2011. In Figure A10a the thick blue line is the volume weighted average of the price of all 12 contracts. Figure A10b reflects that only three contracts have any substantial volume of trades as does A10c. The thick blue line in panel A10d shows the average price volatility of all contracts. 
Figure A11: 2013 Rebar Contracts

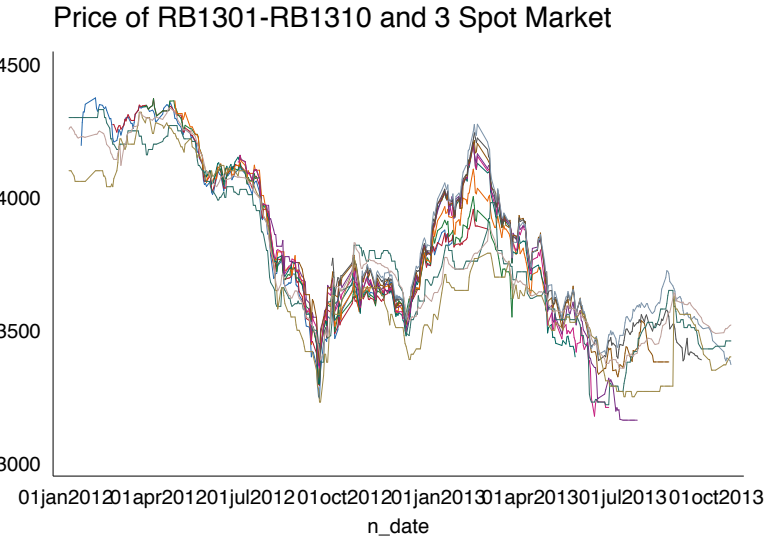

(a) Price

Market Position ofRB1301-RB1310

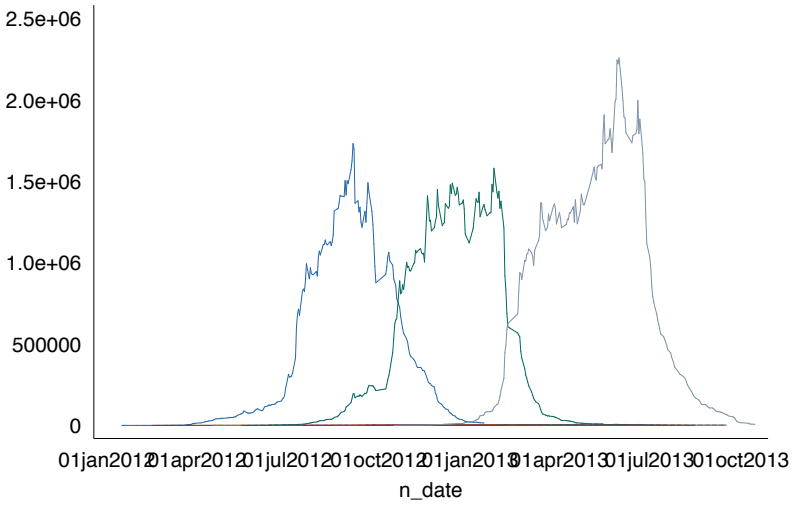

(c) Market Position
Daily Trading Volumes of RB1301-RB1310

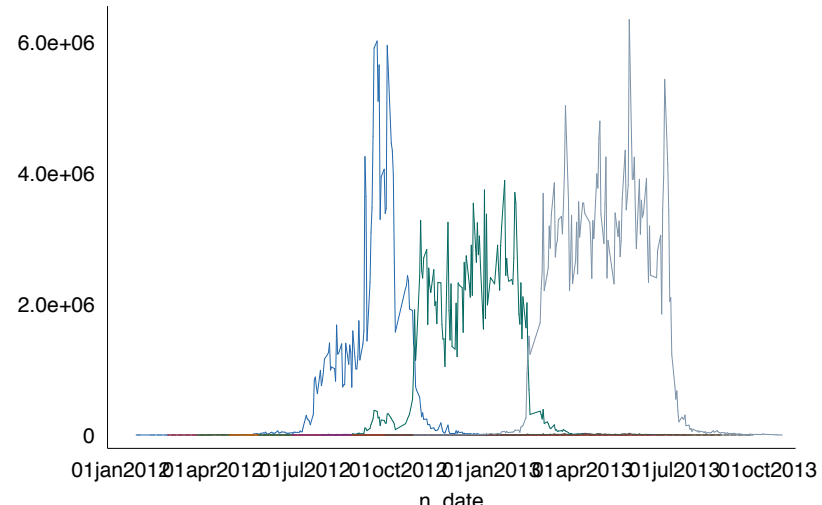

(b) Volume

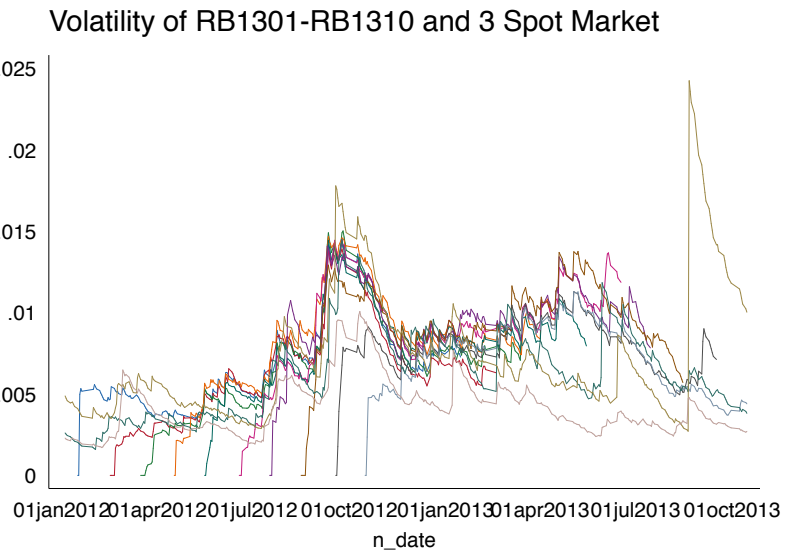

(d) Volatility

Figures describe Price (in RMB), Volume (Contracts), Net Market Position (Open Interest), Volatility (Exponential Moving Average of the Variance of the Log Return $\lambda=0.94$ ) of contracts RB1301-RB1312; that is, contracts for delivery in 2013. In Figure A11a the thick blue line is the volume weighted average of the price of all 12 contracts. Figure A11b reflects that only three contracts have any substantial volume of trades as does A11c. The thick blue line in panel A11d shows the average price volatility of all contracts. 
Figure A12: Monthly Net Steel Imports

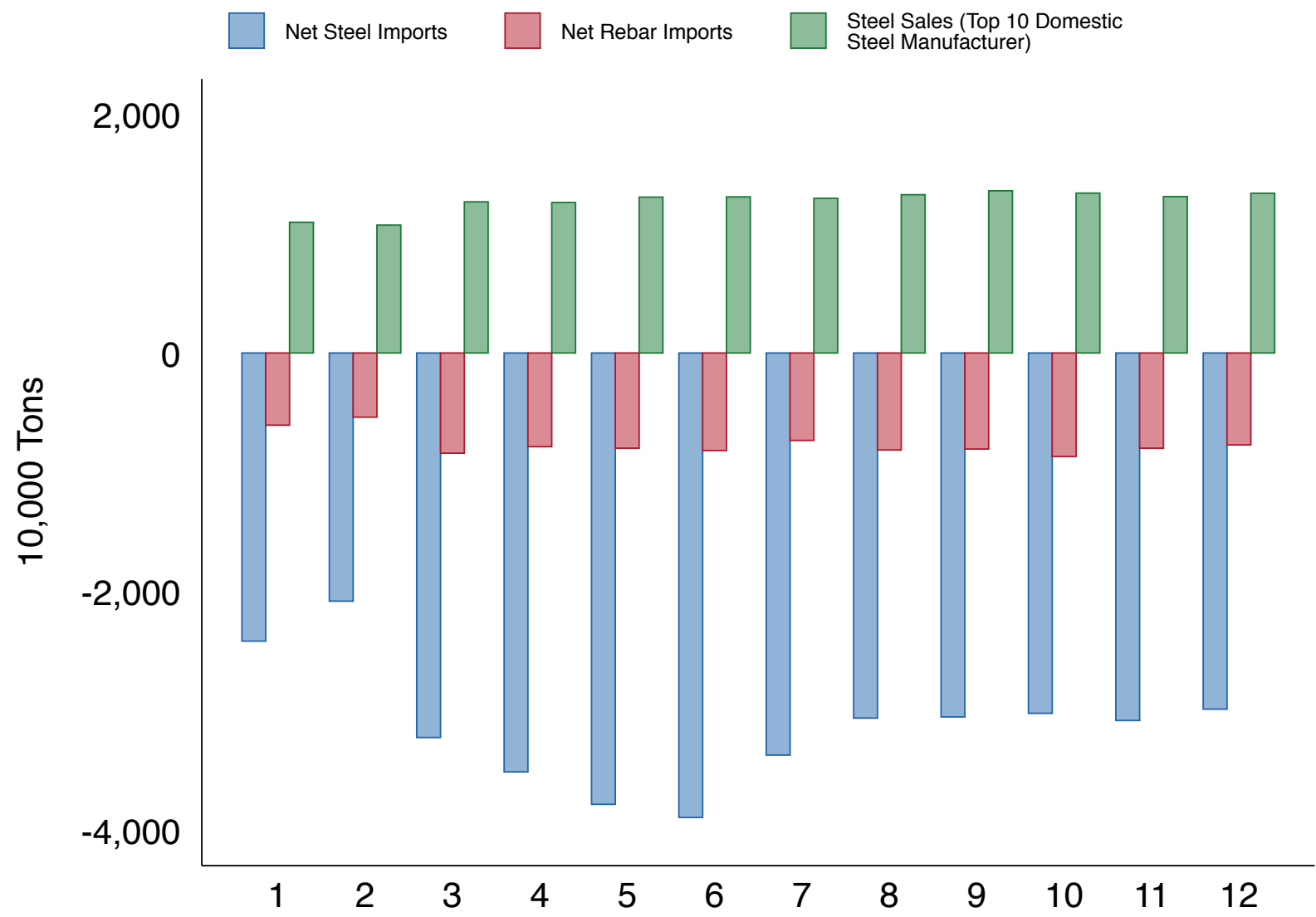

For each month, the graph describes the net imports of all forms of Steel, net imports of Rebar, and the Steel sales of a leading manufacturer. Whilst overall net steel imports fluctuate a little over the year, Rebar imports are comparatively stable with only a small decrease in January and February. Similarly, the sales of the leading Steel manufacturer are relatively constant with a small but perceptible dip in January and February. 
Figure A13: Rebar Spot Prices

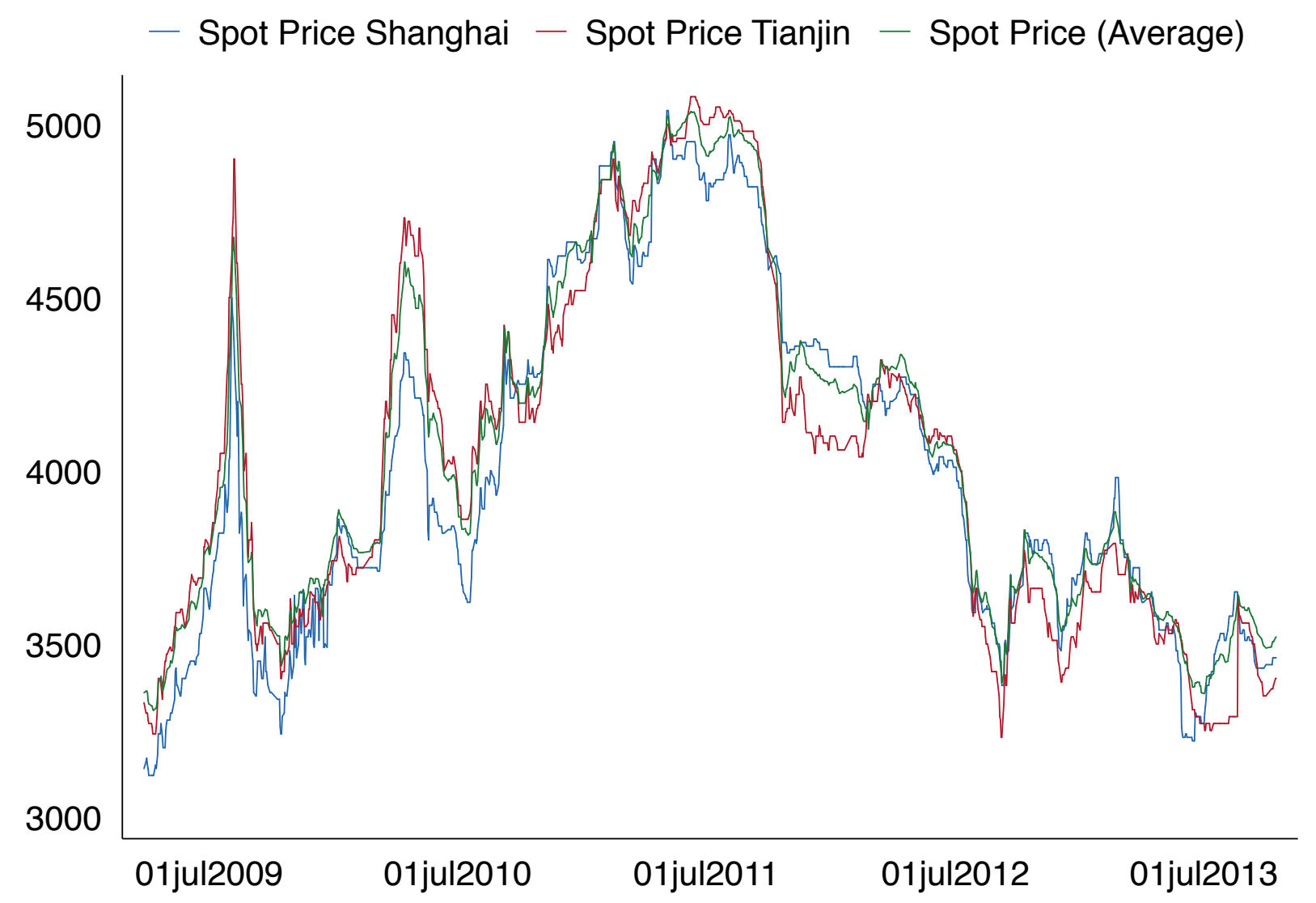

The graph plots the spot price for the Shanghai market as-well as other (smaller) market of Tianjin, and the average of the two. It is clear that, whilst there are sometimes variations between the two, that deviations do not tend to last for more than a few days, except perhaps with the exception of early 2011. 
Figure A14: Price Volatility - Whole Sample

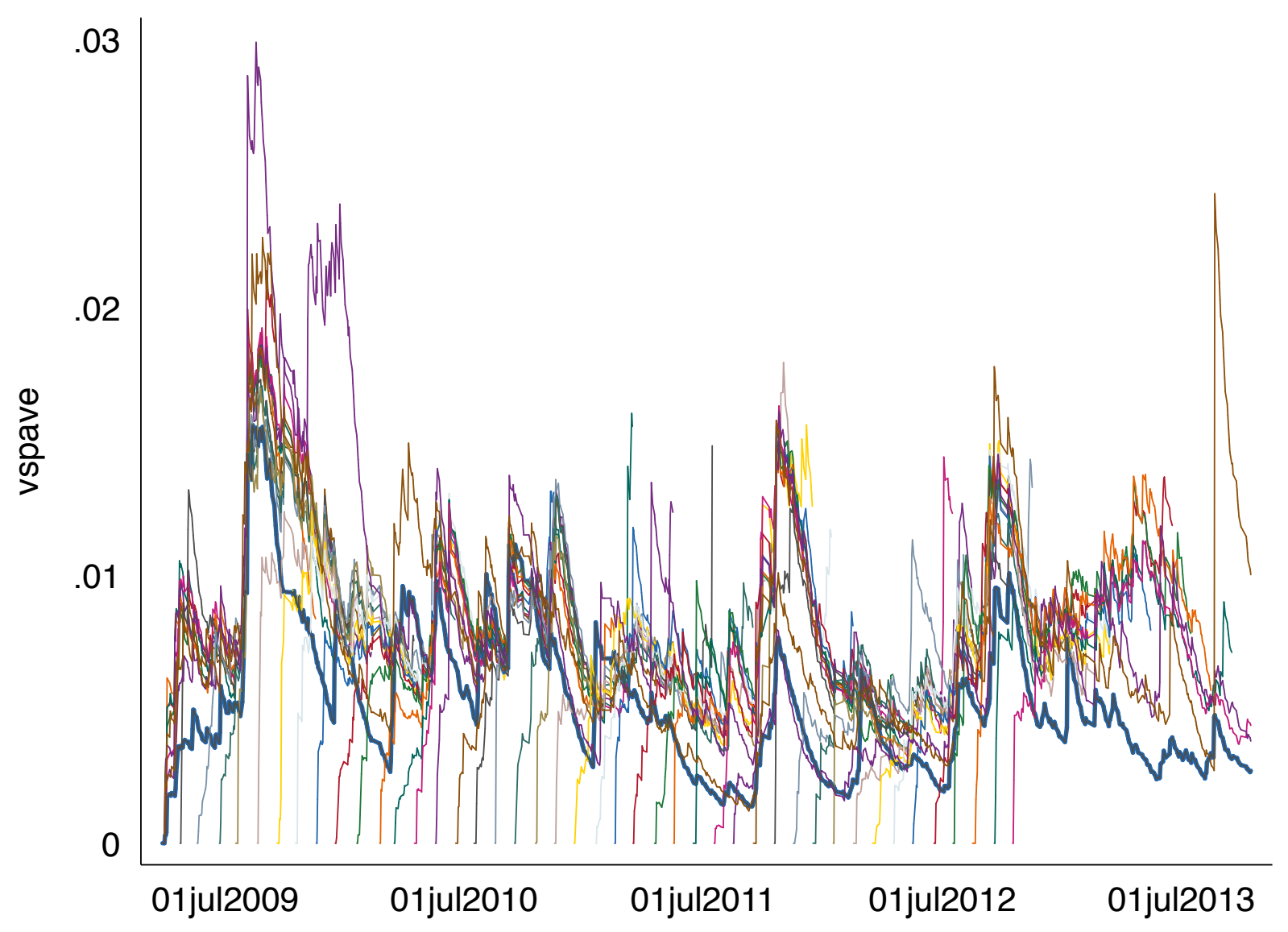

The figure plots the volatility of each contract over its lifetime. The thick blue line is the volume-weighted average volatility across all contracts. 
Figure A15: Market and Limit Orders

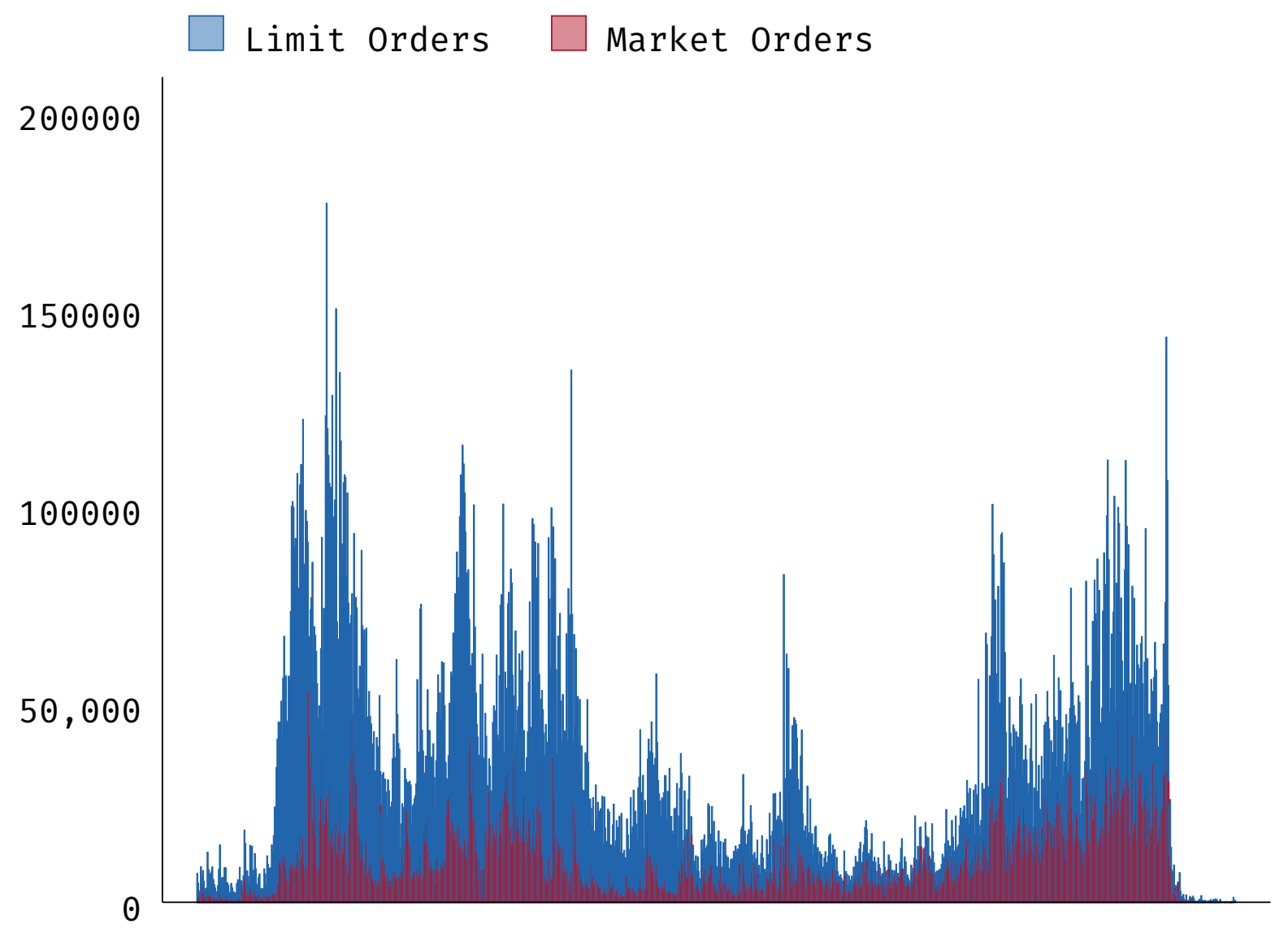

The figure contains a stacked bar-chart describing the total number of daily orders over the sample period, and the proportion of this accounted for by limit and market orders respectively. The preponderance of blue reflects that most orders in the data are limit orders and that the two seem to be in relatively constant proportion over the period. 


\section{B Proof of Proposition 1}

Pender (2015) shows that $X \sim N(q, v)$ with upper and lower truncation points $A$ and $B$ has Skewness:

$$
\operatorname{Skew}(A, B, q, v)=\frac{\left(\frac{h_{2}(\chi) \psi(\chi)-h_{2}(\phi) \psi(\phi)}{\theta(\phi)-\theta(\chi)}-\frac{3(((\chi \psi(\chi)-\phi \psi(\phi))(\psi(\chi)-\psi(\phi)))(\theta(\phi)-\theta(\chi)))}{\theta(\phi)-\theta(\chi)}+\frac{2(\psi(\chi)-\psi(\phi))^{3}}{(\theta(\phi)-\theta(\chi))^{3}}\right)}{\left(1-\frac{(\psi(\chi)-\psi(\phi))^{2}}{(\theta(\phi)-\theta(\chi))^{2}}+\frac{\chi \psi(\chi)-\phi \psi(\phi)}{\theta(\phi)-\theta(\chi)}\right)^{3 / 2}}
$$

Differentiating (11), and setting both the mean, $m=1$, and the variance, $q=1$ with respect to $A$ gives:

$$
\frac{\partial \operatorname{Skew}(X)}{\partial A}=\frac{N}{D}=\frac{N_{1}+N_{2}+N_{3}+N_{4}+N_{5}+N_{6}}{\left(D_{1}+D_{2}\right)^{3 / 2}}
$$

Where:

$$
\begin{aligned}
& N_{1}=\frac{24 e^{-2(A-1)^{2}-\frac{3}{2}(B-1)^{2}}\left(-e^{\frac{1}{2}(A-1)^{2}}+e^{\frac{1}{2}(B-1)^{2}}\right)^{3}}{\pi^{2}\left(\operatorname{erf}\left(\frac{A-1}{\sqrt{2}}\right)-\operatorname{erf}\left(\frac{B-1}{\sqrt{2}}\right)\right)^{4}} \\
& N_{2}=\frac{2(A-2) A e^{-(A-1)^{2}-\frac{1}{2}(B-1)^{2}}\left(-e^{\frac{1}{2}(A-1)^{2}}+e^{\frac{1}{2}(B-1)^{2}}\right)}{\pi\left(\operatorname{erf}\left(\frac{A-1}{\sqrt{2}}\right)-\operatorname{erf}\left(\frac{B-1}{\sqrt{2}}\right)\right)^{2}} \\
& N_{3}=\frac{3(A-2) A e^{-A^{2}+A-\frac{B^{2}}{2}-1}\left(-e^{\frac{A^{2}}{2}+B}+e^{\frac{B^{2}}{2}+A}\right)}{2 \pi} \\
& N_{4}=\frac{3(A-1) e^{-(A-1)^{2}}\left(A-(B-1) e^{\frac{1}{2}(A-B)(A+B-2)}-1\right)}{2 \pi} \\
& N_{5}=\frac{(A-1) e^{-\frac{A^{2}}{2}+A+B-\frac{B^{2}}{2}-1}\left(e^{\frac{1}{2}(B-1)^{2}}((A-2) A-2)+2 e^{\frac{1}{2}(A-1)^{2}}\right) \sqrt{\frac{2}{\pi}}}{\operatorname{erf}\left(\frac{A-1}{\sqrt{2}}\right)-\operatorname{erf}\left(\frac{B-1}{\sqrt{2}}\right)} \\
& N_{6}=\frac{12 \sqrt{2}(A-1) e^{\frac{1}{2}(-3)(A-1)^{2}-(B-1)^{2}}\left(e^{\frac{1}{2}(A-1)^{2}}-e^{\frac{1}{2}(B-1)^{2}}\right)^{2}}{\pi^{3 / 2}\left(\operatorname{erf}\left(\frac{A-1}{\sqrt{2}}\right)-\operatorname{erf}\left(\frac{B-1}{\sqrt{2}}\right)\right)^{3}} \\
& D_{1}=-\frac{2 e^{-(A-1)^{2}-(B-1)^{2}}\left(e^{\frac{1}{2}(A-1)^{2}}-e^{\frac{1}{2}(B-1)^{2}}\right)^{2}}{\pi\left(\operatorname{erf}\left(\frac{A-1}{\sqrt{2}}\right)-\operatorname{erf}\left(\frac{B-1}{\sqrt{2}}\right)\right)^{2}} \\
& D_{2}=\frac{\left((A-1) e^{-\frac{1}{2}(A-1)^{2}}-(B-1) e^{-\frac{1}{2}(B-1)^{2}}\right) \sqrt{\frac{2}{\pi}}}{\operatorname{erf}\left(\frac{B-1}{\sqrt{2}}\right)-\operatorname{erf}\left(\frac{A-1}{\sqrt{2}}\right)}+1
\end{aligned}
$$


We consider the relevant case where there is only lower truncation, that is $B=\infty$. Some tedious algebra gives:

$$
\left.\frac{\partial \text { Skew }}{\partial A}\right|_{B=\infty}=\frac{3(A-1)^{2} e^{-(A-1)^{2}}}{2 \pi\left(1-\frac{\sqrt{\frac{2}{\pi}}(A-1) e^{-\frac{1}{2}(A-1)^{2}}}{\operatorname{erf}\left(\frac{A-1}{\sqrt{2}}\right)}\right)^{3 / 2}}>0
$$

Given that $A \neq 1$, this is always positive confirming that the Skewness is almost everywhere increasing in the truncation point.

\section{Optimal Portfolio}

We initially consider empirically the composition of the Optimal Portfolio. This composition depends on the set of assets available. We obtained daily price-data for around 8,500 other financial assets and commodities available to Chinese investors. Note, that limitations on foreign investment mean that we can be confident this represents, broadly speaking, the universe of available financial investments. $^{21}$ We exclude real estate assets, as the implied investment size and time horizon for such investments is very different to that observed for Rebar, and thus, it is implausible that Rebar could be part of hedging strategy for such assets. Solving for the optimal portfolio for a broad range of time periods and time horizons we never find that margin-traded Rebar are included. Were it not for the substantial negative return this would be surprising as normally one would expect, if there were no constraints on the number of assets in the portfolio, all assets to have a positive weight. One might alternatively attribute this result to the consistent negative trend across the period; but, given that traders could open short or long positions this argument carries little weight.

\section{Trading Periods Algorithm}

A given sub-period may be regarded as a group of trades that are close together in time and separated from other groups of trades by a period of no trades. We identify these periods separately for each individual automatically using the k-means algorithm. This looks at the history of an individual's trading volumes (or total position size). The optimal number of clusters for each trader is determined by applying an automated version of the 'elbow' heuristic. This approach identifies the number of clusters such that adding additional clusters only has a small effect on explaining further variance. The optimal number of clusters is then the point in variance explained/clusters space that is furthest form the 45 degree line - the elbow or corner in the graph of variance explained against clusters. For example, in the case presented in Figure A16 this suggests that 4 is the optimal number of clusters.

\footnotetext{
${ }^{21}$ This list is available upon request.
} 
Figure A16: Identifying the Number of Separate Trading Episodes

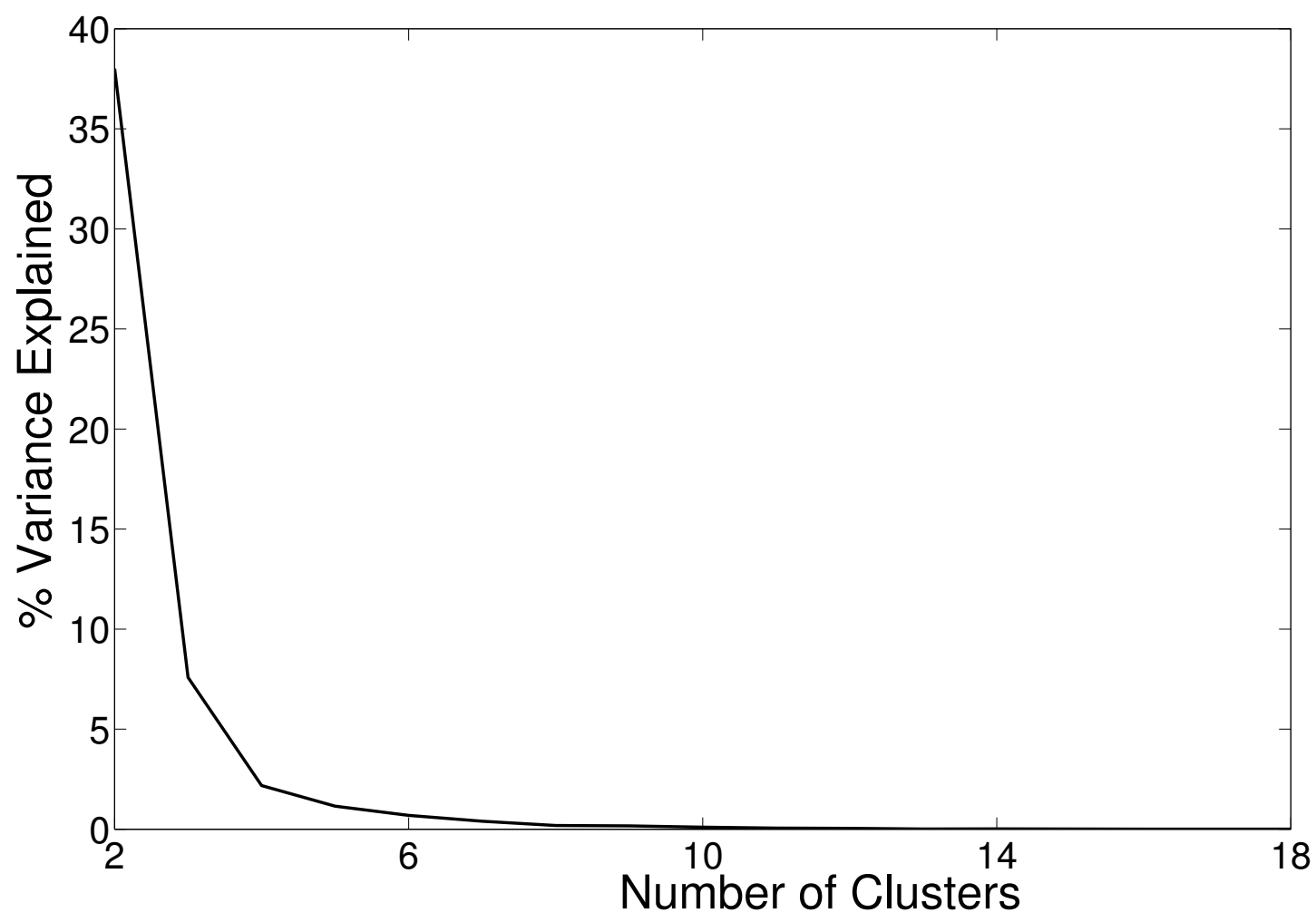

The vertical axis reports the proportion of variance explained by the last cluster while the horizontal axis reports the total number of clusters. Thus, in the example the second cluster explains around $40 \%$ of the variance, the third around $7 \%$ the fourth around $3 \%$, and the $18^{\text {th }}$ approximately $0 \%$ of the variance.

Alternative clustering algorithms such as hierarchical clustering were also considered and did not qualitatively change the results. 